DOI

http://dx.doi.org/10.1590/2236-463320151113

"They don't obey anyone, but each one rules their own family". Ethnicity and policy in the reducción of bahoruco maniel, 1785-1795

"Não obedecem a ninguém, mas cada um governa a sua familia". Etnicidade e política na reducción do quilombo de Bahoruco, 1785-1795

\section{"No obedecen a nadie, sino cada uno gobierna a su familia". Etnicidad y política en la reducción del maniel de Bahoruco, 1785-1795}

\section{José Luís Belmonte Postigo}

Universidad Pablo de Olavide, Sevilha, Espanha

\begin{abstract}
Resumen
En el proceso de negociación para la reducción del maniel de Bahoruco, radicado en la frontera entre Santo Domingo y Saint Domingue, intervinieron tanto las autoridades españolas y francesas como los cimarrones. La comunidad cimarrona no conformaba un corpus político unificado, sino que estaba dividida en dos grupos con identidad definida, líderes diferenciados y propuestas políticas propias. A lo largo del proceso de negociación, que se vio seriamente afectado por la revolución haitiana, los posicionamientos políticos de los dos grupos de cimarrones fué divergente, atendiendo a las necesidades específicas de cada uno de los grupos.
\end{abstract}

\section{Abstract}

Spanish and French authorities, as well as the maroons, participated of the process of negotiation for the reducción of Bahoruco maniel, sited in Saint Domingue/Santo Domingo border. The maroon community was divided in two different groups, each of them with their own identities, leaderships and policies. During the negotiation, which was affected by the Haitian Revolution, each maroon group followed separated strategies in order to satisfy their own necessities.

\section{Resumo}

Durante a negociação para a reducción do quilombo de Bahoruco, situado na fronteira entre Saint Domingue e Santo Domingo, participaram as autoridades espanholas, francesas e a própria comunidade quilombola. A comunidade estava dividida em dois grupos, com suas próprias identidades, lideranças e políticas. A negociação foi afetada pela Revolução Haitiana, e cada grupo quilombola seguiu estratégias distintas para satisfazer as suas particulares necessidades idiossincráticas.

Palabras claves

Esclavos, cimarrones, Santo Domingo, Identidad, Revolución haitiana

Keywords

Slaves, Maroons, Santo Domingo, Identity, Haitian Revolution

Palavras-chave

Escravos, quilombo, Santo Domingo, Identidade, Revolução Haitiana. 
1

*Queremos agradecer a los profesores Luiz Geraldo Silva, Rachel O'Toole y José Buscaglia Salgado la atenta lectura a versiones previas de este texto, asi como sus comentarios e ideas que sin duda han ayudado a enriquecerlo. También queremos destacar la labor de los evaluadores anónimos que trabajaron sobre el texto, cuyas críticas constructivas mejoraron el resultado final. En Santo Domingo se conocía por "maniel" a un asentamiento constituido por personas que vivian al margen de las instituciones coloniales, principalmente esclavos fugitivos, aunque también contrabandistas, personas sin residencia fija 0 fugitivos de la justicia, ubicado en un territorio de dificil acceso, por lo general, en las sierras que jalonan buena parte de la geografía dominicana.

2

Carta del Cabo Rojas al Gobernador de Santo Domingo (Neiba, 18 de agosto de 1785), Archivo General de Indias (en adelante AGI), Santo Domingo 1102.

3

MOREAU DE SÀINT- MARI, M.I.E. The Border Maroons of Saint Domingue: Le Maniel. In: PRICE, Richard (ed.) Maroon Societies. Rebel Slave Communities in the Americas. Baltimore: The John Hopkins University Press, 1996. p. 135-142. En opinión del autor, el cambio de actitud de los arrochelados vino determinado por la acción de varios vecinos españoles de la zona fronteriza que se lucraban con el comercio con el maniel. Estos se habian dedicado a difundir rumores sobre las verdaderas intenciones de los franceses, que no eran otras que infligirles un duro castigo en cuanto cruzaran la frontera.

Informe del Arzobispo de Santo Domingo (Santo Domingo, 3 de enero de 1790) AGI, Santo Domingo 1102.

5

HAHN, Steven. The Political Worlds of Slavery and Freedom. Cambridge: Harvard University Press, 2009. p. 24
El 26 agosto de 1785, el Capitán de Dragones de las tropas nacionales del Saint Domingue Jean Marie Desmarates tuvo que detener su camino hacia Neiba. Debido a una gran tormenta, que terminó convirtiéndose en un huracán, el comisionado debió esperar pacientemente a que el tiempo mejorase para poder cumplir con su cometido; poner fin al palenque que, compuesto en su mayoría por esclavos procedentes del Saint Domingue, se había situado en las cercanías de la villa de Neiba, en las sierras de Bahoruco. Desde alli, sus pobladores cruzaban con frecuencia la frontera asaltando haciendas y capturando (o liberando) esclavos. El maniel se había convertido en lugar de asilo de cimarrones, además de constituir un peligroso ejemplo para el orden esclavista de la colonia francesa, que veía con preocupación su posible consolidación en el territorio fronterizo. ${ }^{1}$

Con el apoyo de las autoridades civiles y eclesiásticas de la parte española, se habia producido un principio de acuerdo encaminado a su eliminación y a la devolución de los cimarrones al lado francés. Éstos, en principio, aceptaban su traslado para fundar un pueblo de negros libres, comprometiéndose a la destrucción del asentamiento de Bahoruco para evitar que pudiera ser ocupado por otros grupos cimarrones. El acuerdo, así como la forma en la que podía ser llevado a cabo, debía concretarse en una reunión en Neiba que debía celebrarse con cierta premura. Sin embargo, la irrupción del huracán y el calamitoso estado en el que quedaron los principales caminos de la región por las fuertes Iluvias caídas, obligaron a la comisión francesa a retrasarse. Cuando Desmarates finalmente llegó a la villa, las autoridades españolas le confirmaron que los apalencados se habían marchado, que su retraso los había llenado de temor y que preferían vivir en las montañas antes que regresar a la parte francesa, a la que sólo irían si antes los mataban. ${ }^{2}$ Se rompía de esta forma, un principio de acuerdo que había tardado dos años en cristalizar, y que había obligado a contactos políticos de primer nivel entre las cortes española y francesa. El retraso del delegado francés fue utilizado como excusa por los arrochelados, quienes negaban la posibilidad de establecerse como pueblo de hombres libres en territorio francés, ya que suponían que las autoridades coloniales desconocerian los acuerdos en el mismo momento en el que cruzaran la frontera. ${ }^{3}$ Todo quedó en papel mojado, si bien los contactos se mantuvieron para tratar de llegar a un principio de acuerdo que permitiera una solución satisfactoria a todos los implicados. Sin embargo, el complicado contexto que se abriría con el proceso revolucionario, primero en Francia y luego en la colonia de Saint Domingue, modificó sustancialmente las estrategias de los principales actores de la negociación. ${ }^{4}$ La comunidad cimarrona, inmersa en el contexto revolucionario, no se sumó a la gran revuelta de esclavos de 1791, estableciendo tácticas políticas diversas encaminadas a satisfacer las demandas que planteaban en base a sus propias necesidades. ${ }^{5}$ El maniel de Bahoruco ha sido objeto de atención por parte de la historiografía por ser una de las pocas comunidades cimarronas a las que se ha podido estudiar en su desenvolvimiento político en los primeros años del proceso revolucionario del Saint Domingue. La ubicación del maniel en el espacio fronterizo entre las dos colonias, ha sido tratado por autores como Rosario Sevilla Soler, Moreau de Sàint Mary o Mendes Queiroz, que han hecho énfasis en la conformación de un territorio cimarrón, alejado de los centros de poder metropolitano francés y español, que fue defendido y detentado con éxito por parte de los arrochelados. Yvan Debbasch señala que la existencia de este territorio cimarrón era percibida como un freno para la expansión de 
6

SEVILLA SOLER, Rosario. Santo Domingo tierra de frontera, 1750-1800. Sevilla: Escuela de Estudios Hispanoamericanos, 1980

7

MOYA PONS, Frank. Historia del Caribe, azúcar y plantaciones en el mundo atlántico. Santo Domingo: Ediciones Ferilibro, 2008.

8

BLACKBURN, Robin. The Making of New World Slavery: From the Baroque to the Modern, 14921800. Londres: Verso, 2002. pp. 281-292.

LUCENA SALMORAL, Manuel. Leyes para esclavos: el ordenamiento jurídico sobre la condición, tratamiento, defensa y represión de los esclavos en las colonias de la América española. Madrid, Editorial Tavera, 2000. p. 296-316 la frontera agrícola por parte de los colonos franceses, quienes observaban las sierras de Bahoruco como un lugar preferente donde poder seguir fomentando el cultivo del café. De otro lado, Lienhard centró su estudio en la descripción de los actores de la negociación, identificando al interior de la comunidad cimarrona dos facciones distintas, cuya divergencia fundamental era política, esto es, su actitud más o menos receptiva a la negociación con las autoridades coloniales española y francesa. Finalmente, los trabajos de David Geggus han señalado la importancia de este maniel para entender la participación de los cimarrones en el momento inicial del proceso revolucionario del Saint Domingue, insinuando, además, conexiones entre el maniel de Neiba y otras comunidades cimarronas al otro lado de la frontera. En nuestro trabajo, pretendemos mostrar la conformación del maniel y señalaremos como las estrategias políticas seguidas por los arrochelados durante el proceso de negociación fueron consecuencia de su conformación indentitaria. Esto es, la creación de identidades colectivas diferenciadas en el interior del maniel en base a su background cultural, a la brutal experiencia de la esclavitud y a la condiciones de vida durante el cimarronaje, favoreció la creación de proyectos políticos divergentes al interior de la comunidad, lo que condicionó el proceso de negociación que se desarrollaba de manera paralela con las autoridades coloniales de España y Francia.

Una isla con (al menos) dos historias

La reducción del maniel de Bahoruco puso sobre la mesa uno de los principales problemas a los que debieron hacer frente tanto Madrid como Paris durante buena parte del siglo XVIII, la ocupación y gestión del territorio en la isla de La Española. El avance de la frontera agrícola en la parte francesa se tradujo en un avance continuado de la frontera política que separaba a las dos colonias. ${ }^{6}$ La instalación progresiva de habitaciones de café y haciendas azucareras a todo lo largo de la frontera, tuvo su plasmación en sucesivos acuerdos diplomáticos que trataron de establecer de manera firme los límites de la soberanía entre la dos potencias. Si bien estos acuerdos no eran más que la ratificación de situaciones que se daban de facto, su revalidación frecuentemente quedaba sin efecto por la acción de los colonos franceses que, ante el aparente abandono de tierras protagonizado por sus vecinos españoles, no dudaron en ocuparlas. ${ }^{7}$

El crecimiento de los cultivos de exportación en Saint Domingue se fundamentaba en la importación masiva de mano de obra esclava. A lo largo de la segunda mitad del siglo XVII, la política mercantilista francesa había favorecido la entrada en sus posesiones americanas de un número significativo de esclavos. El avance del esclavismo urgió a las autoridades a establecer una normativa uniforme en el tratamiento de los esclavos, lo que fue sancionado en 1685, con la promulgación del Code Noir. Si bien una de las principales motivaciones para el establecimiento de nuevo marco legal era evitar el tratamiento "enfermizo" de los propietarios, lo cierto es que el mismo otorgaba un poder casi omnímodo al propietario. ${ }^{8} \mathrm{Se}$ permitían los más severos castigos, se imposibilitaba el acceso a los tribunales de justicia a los esclavos, se condicionaba su capacidad para contraer matrimonio y se restringía, de manera muy importante, su capacidad para conseguir la libertad a través de la manumisión. ${ }^{9} \mathrm{Al}$ mismo tiempo, la Monarquía francesa implementó los mecanismos a su alcance para introducir la mano de obra esclava que requería para el desarrollo de las economías de plantación. Para ello, contaba con una importante estructura de facto- 
10

http://www.slavevoyages.org/tast/assessment/ estimates.faces

GEGGUS, David Patrick. Sugar and Coffee Cultivation in Saint Domingue and the Shaping of the Slave Labor Force. In: BERLIN, Ira and MORGAN, Philip. Cultivation and Culture: Labor and the Shaping of Slave Life in the Americas. Charlottesville: University of Virginia Press, 1993. p. 73-98.

TOMICH, Dale. Commodity Frontiers, Conjuncture and Crisis: The Remaking of the Caribbean Sugar Industry, 1783-1866. In: LAVIÑA, Javier and ZEUSKE, Michael (eds). The Second Slavery. Mass Slaveries and Modernity in the Americas and in Atlantic Basin. Berlin: Lit Verlag, 2014. pp. 143-164. rías comerciales en África occidental, que, desde la segunda mitad del siglo XVII posibilitó a los franceses disponer de un contacto directo con diversos estados costeros africanos de los que obtenían, entre otras mercaderías, mano de obra esclava. Sin embargo, no fue hasta las primeras décadas del siglo XVIII cuando el comercio negrero francés se articuló de manera más efectiva. Al incremento de la presencia francesa en África occidental, en dura competencia de los mercantes ingleses, se sumó la fundación de diversas colonias en el este africano que, gracias a la Compañía de las Indias Orientales, permitió establecer nexos más fluidos, constantes y diversificados con los diferentes proveedores de esclavos.

La preeminencia del Saint Domingue como la colonia esclavista más importante de los dominios franceses en América no tardó en establecerse. Desde comienzos del siglo XVIII hasta el estallido revolucionario haitiano de 1791, casi un millón de esclavos fueron introducidos en los diferentes puertos de la colonia..$^{10}$ La importación de esclavos se incrementó en la década de los ochenta del siglo XVIII, cuando la inestabilidad económica de la metrópoli, generada en buena medida por la participación francesa en la guerra de independencia de los Estados Unidos, convirtió la inversión en el negocio esclavista de la colonia en una opción preferente para los comerciantes de la metrópoli. El capital mercantil procedente de los principales puertos dedicados a la trata transatlántica, como Burdeos, Le Havre o Marsella, fue utilizado para la compra de esclavos, de tierras y de maquinaria en Saint Domingue. Estas dotaciones de esclavos se orientaban, principalmente, al fomento de los cultivos de caña de azúcar, café o añil. Entre 1763 y 1791 el desarrollo de los modelos azucarero y cafetalero convirtió a la colonia francesa en el principal productor mundial de estos productos. Desde las Ilanuras del Artibonite donde se radicaron buena parte de las haciendas azucareras, a las regiones montañosas del sur donde se asentaron las principales habitaciones de café, la progresiva ocupación del territorio trajo consigo un avance continuado de la frontera agrícola. ${ }^{11}$ La alta demanda del mercado internacional de azúcar y café ofrecía los estímulos necesarios para que en la colonia francesa se siguieran desarrollando estos modelos económicos e impulsara la expansión de los cultivos de exportación. La escasez de tierras cultivables incentivó a los colonos franceses a traspasar la frontera política con Santo Domingo, ocupando territorios que estaban bajo soberanía española, lo que provocó contactos y acuerdos de primer nivel entre las cortes española y francesa para redelinear políticamente el espacio colonial.

En el proceso de redefinición, o expansión, de la economía mundo, regiones como Saint Domingue tenían una gran interdependencia con la reestructuración de los mercados mundiales del azúcar y con la división atlántica del trabajo. ${ }^{12}$ La coyuntura posterior a 1783 estuvo marcada por el auge del esclavismo en la colonia francesa, elevando, de manera consecuente, los niveles de tensión que acumulaba la sociedad esclavista. En este preciso contexto, las autoridades francesas decidieron, de común acuerdo con las españolas, y ante la imposibilidad de derrotar militarmente al maniel, establecer los canales de comunicación más efectivos para terminar con el palenque, que era visto como una seria amenaza, no tanto por los asaltos a las haciendas y los daños a particulares que podían realizar, sino por el ejemplo que suponía para el resto de los esclavos. Además, el maniel ocupaba un amplio territorio fronterizo que era apetecido por los colonos franceses. Éstos, que habían provocado y protagonizado el avance 
DEBBASCH, Yvan. Le maniel: Further Notes. In: PRICE, Richard (ed.) Maroon Societies. Rebel Slave Communities in the Americas. Baltimore: The John Hopkins University Press, 1996. p. 145.

14

GONZÁLEZ, Raymundo. De esclavos a campesinos. Vida rural en Santo Domingo colonial. Santo Domingo: Archivo General de la Nación, Vol. CXLVIII, 2011. En 1767 había 29 ingenios azucareros en la zona de Santo Domingo, los mayores trabajados por 35 o 40 esclavos, p. 75-76.

15

KARRAS, Allan. Transgressive Exchange. Circumventing Eighteenth Century Atlantic Commercial Restrictions or the Discount of Monte Christi. In: BENTLEY, Jerry, BRIDENTHAL, Renate and WIGEN, Karen. Seascapes. Maritime Histories, Littoral Cultures and Transoceanic Exchanges. Honolulu: University of Hawaii Press, 2007. pp. 121-133.

16

GUTIÉRREZ ESCUDERO, Antonio. Acerca del proyectismo y del Reformismo Borbónico en Santo Domingo. Temas Americanistas, Sevilla, № 13, p. 45-67, 1997.

17

GUTIÉRREZ ESCUDERO, Antonio. Hispaniola's turn to tobacco: Products from Santo Domingo in Atlantic Commerce. In: ARAM, Bethany and YUN Bartolomé (eds.). Global Goods and the Spanish Empire, 1492-1824. Circulation, Resistence and Diversity. Basingstoke: Palgrave Macmillan, 2014 pp. 216-229.

18

WIDMER, Rudolf. El Hato ganadero del Este en la economía de Santo Domingo en el siglo XVIII. Con Antonio Sánchez Valverde en San Dionisio de Higüey, Clío, Órgano de la Academia Dominicana de la Historia, Santo Domingo, № 165, enerojunio 2003, pp.143-158.

19

GUTIÉRREZ ESCUDERO, Antonio. El tabaco de Santo Domingo y su exportación a Cádiz y Sevilla, Revista Hispanoamericana. Revista Digital de la Real Academia Hispano Americana de Ciencias, Artes y Letras, No1, p.1-13, 2011.

20

NESSLER, Graham. The shame of the nation. The force of the re-enslavement and the law of the slavery under the regime of Jean Louis Ferrand in Santo Domingo, 1804-1809. New West Indian Guide, Leiden, Vol. 86, 1-2 , p. 7, 2012.

21

BELMONTE POSTIGO, José Luis. Las dos caras de una misma moneda. Reformismo y Esclavitud en Santo Domingo a fines del periodo colonial. Revista de Indias, Madrid, Vol. 74, № 261, p. 453 482, 2014.

22

ZEUSKE, Michael. Estructuras e identidad en la segunda esclavitud: el caso cubano 1800-1940. Historia Crítica, Bogotá, № 24, p. 125-140, 2003. 23

GEGGUS, David Patrick. Slave Resistance in the Spanish Caribbean in the Mid-1790. In: GASPAR, David Barry and GEGGUS, David Patrick. de la frontera política del Saint Domingue, habían fijado su atención en el territorio controlado por los cimarrones, que era percibido, dada la nula presencia institucional española, como un obstáculo para el fomento de cultivos de exportación como el café. ${ }^{3}$ De ésta manera, el avance de la frontera agrícola francesa colisionaba con el territorio cimarrón ocupado y controlado por el maniel, lo que impulsó a las autoridades francesas a buscar una solución al conflicto, bien por la vía militar, o bien por la vía diplomática.

Si el siglo XVIII de Saint Domingue fue un periodo dominado por el desarrollo de los sistemas de plantación y la entrada masiva de mano de obra esclava, el Santo Domingo español experimentó una situación bien distinta. Ante el marasmo económico que envolvía la colonia, las autoridades pretendieron, especialmente en la segunda mitad del siglo XVIII, establecer una serie de medidas que revitalizaran los sectores económicos potencialmente rentables. El conjunto de reformas políticas, fiscales y mercantiles que la Monarquia Hispánica aplicó al conjunto de sus dominios americanos durante éste periodo tuvieron en Santo Domingo un efecto limitado. Si bien tales medidas permitieron un importante repunte económico en territorios como Cuba, Puerto Rico o Venezuela, que pasaron de ser consideradas áreas marginales del imperio español a espacios altamente productivos y rentables para la Real Hacienda, Santo Domingo experimentó un desarrollo más modesto. En buena medida, las reformas no lograron desarrollar, como lo hubieran deseado las autoridades coloniales, el tejido productivo azucarero, ${ }^{14}$ el sector minero, el comercial ${ }^{15}$ o el cultivo del tabaco, ${ }^{16}$ si bien este último tuvo un resurgimiento importante hasta el año 1774, cuando la Corona impuso restricciones importantes a las exportaciones tabacaleras dominicana. ${ }^{17}$ Los cortes de maderas $y$, sobre todo, el ganado, ${ }^{18}$ constituyeron los principales rubros productivos en las últimas décadas del siglo XVIII. ${ }^{19}$ Este tipo de explotaciones no requerian de un gran número de esclavos, hasta tal punto que, según Nessler, la población esclava en Santo Domingo en los albores del proceso revolucionario haitiano apenas alcanzaba el $15 \%$ del total. ${ }^{20}$ La escasa implantación de los sistemas de plantación en Santo Domingo tuvo una incidencia importante en las condiciones de vida de gran parte de los esclavos radicados en la colonia española, a pesar de que las autoridades hispánicas tratasen de implementar nuevas formas de tratamiento más severas. ${ }^{21}$ Como señala Zeuske, estas condiciones dependian, por encima de la región donde estuviera radicado el sujeto esclavizado, de la orientación laboral a la que su propietario lo hubiera destinado..$^{22}$ Dado el escaso desarrollo de los modelos de plantación en territorio dominicano, las formas de explotación laboral diferian notablemente con las que se implementaban en el lado francés. Claro que esto no implica lanzar una velada defensa de la amabilidad del sistema esclavista dominicano. En las haciendas azucareras que se desarrollaron, la dureza de las condiciones de vida del esclavo era comparable a las de otras regiones. ${ }^{23}$ Sin embargo, la importancia de la esclavitud de jornal, tanto en el campo como en la ciudad, y el importante rol de los esclavos en el sector ganadero, fueron decisivos para el desarrollo de las relaciones esclavistas al interior de la colonia. ${ }^{24}$

Dada la demanda existente de vacuno en la región Caribe, principalmente en las vecinas colonias extranjeras, el desarrollo ganadero dominicano respondía a una lógica estructuración económica de tipo regional. ${ }^{25}$ En territorios como Jamaica, Grenada, Dominica, Saint Vicent, Las Granadinas, Tobago, Barbados o, de vital importancia para el caso que nos ocupa, 
A Turbulent Time, The French Revolution and the Greater Caribbean. Bloomington: Indiana University Press, 1997, pp.131-155.

\section{4}

BELMONTE POSTIGO, José Luis. De cómo la costumbre articula derechos. Esclavos en Santo Domingo a fines del periodo colonial. In: LAVIÑA, Javier; PIQUERAS Ricardo y MONDEJAR, Cristina (eds.). Afroamérica, espacios e identidades. Barcelona: Editorial Icaria, 2013. p. 65-92.

25

MOYA PONS, Frank. Manual de Historia Dominicana. Santo Domingo: Caribbean Publishers, 2008. p. 121.

26

MOYA PONS, Frank. Historia del Caribe, azúcar y plantaciones en el mundo atlántico. Santo Domingo: Ediciones Ferilibro, 2008. p. 197-203. Indias en pleno de las dos salas (Madrid, 29 de mayo 1788), AGI, Santo Domingo 1102.
Saint Domingue, el esclavismo había adquirido una extraordinaria dimensión que había provocado que buena parte de los sectores económicos que estaban orientados a satisfacer las demandas internas fueran desplazados por el fomento de productos de exportación como el azúcar, el café o el añil. ${ }^{26} \mathrm{El}$ crecimiento económico experimentado en la colonia francesa de Saint Domingue difícilmente hubiera podido llevarse a cabo sin el abasto de carnes que procedian del Santo Domingo español, lo que ligaba, desde un punto de vista económico, la vida de las dos colonias. Esta imbricación tuvo importantes consecuencias para la estructura económica de Santo Domingo. La extensión del hato ganadero, y las dificultades con las que contó el desarrollo de los modelos de plantación azucareros, habilitó un tipo de ocupación y explotación del territorio distinto al del Saint Domingue, donde la concentración de la población en las cercanias de ciudades o pueblos contrastaba con la ocupación dominicana del territorio, caracterizada por disponer de una población campesina dispersa tanto en tierras comunales como de particulares, alejadas de los principales centros poblacionales. Este hecho favoreció el paulatino avance de la frontera agrícola, y por ende política, desde Saint Domingue, pero además habilitaba, especialmente en territorios de orografía difícil o con escasa presencia institucional, espacios que servian de refugio a los esclavos que se fugaban de sus propietarios. La sierra de Bahoruco, próxima a la frontera, era una región poco conocida y transitada por las autoridades coloniales por su dificultad orográfica y el escaso interés económico que despertaba su explotación: Este espacio, ignorado u olvidado por casi todos, se convirtió, de facto, en territorio cimarrón, sin que las autoridades españolas hubieran podido arbitrar medios efectivos para su control. La existencia de un palenque en las sierras de Bahoruco respondía, por tanto, a la lógica de la ocupación y explotación del territorio dominicano así como al incremento del número de esclavos y de las formas de explotación del trabajo en el lado francés de la frontera.

La cercanía del espacio cimarrón a Saint Domingue, que experimentaba un extraordinario auge del esclavismo, suponía una gran preocupación para las autoridades francesas, asi como un freno para la expansión de su frontera agrícola. El cimarronaje, como fenómeno de resistencia, implicaba un replanteamiento de la institución de esclavista, ya que con la huida el esclavo negaba cualquier posibilidad al propietario de captar su trabajo y, al mismo tiempo, refutaba e imposibilitaba la aplicación del dominio. A través del cimarronaje, los esclavos recuperaban una parte de su capacidad para decidir sobre su destino, si bien existían condicionantes, como la percepción del entorno social o los peligros que debian afrontar ante la constante amenaza de captura y el consecuente castigo aplicado por los propietarios, que lo mediatizaba.

\section{Reconstruyendo el maniel}

Los orígenes de la ubicación de ésta comunidad habría que buscarlos en las sierras de Neiba, cerca de las lagunas ubicadas al noroeste de la ciudad. Ya en el año 1749, en ese mismo territorio, las autoridades locales realizaron un proceso de negociación con un pequeño palenque que llevó consigo su reducción, consiguiendo los apalencados una serie de prerrogativas, la más importante, el reconocimiento tácito de no devolverlos a la colonia francesa. ${ }^{27}$ Esta experiencia tendría posterior influencia en los procesos de negociación con el maniel que nos ocupa, dado el papel destacado que 
Informe del Gobernador de Santo Domingo sobre lo actuado por el Arzobispo (Santo Domingo, 25 de diciembre de 1787), AGI, Santo Domingo 947.

29

SEVILLA SOLER, Rosario. Santo Domingo, frontera franco-española. Consecuencias de la presencia francesa en la Isla de la Española. Revista de Indias, Madrid, Anexos 4, 1991, p. 167

30

GEGGUS, David Patrick. Haitian Revolutionary Studies. Bloomington: University of Indiana Press, 2002, p. 78.

31

LIENHARD, Martin. Agrestes e irreligiosos. Los cimarrones del maniel de Neiva (Santo Domingo 1784-1795). In: LIENHARD, Martin. Disidentes, rebeldes, insurgentes Resistencia indigena y negra en América Latina. Ensayos de historia testimonial. Madrid: Iberoamericana Vervuert, 2008 p. 85. jugaron los eclesiásticos dominicanos, quienes se abrogaron un importante papel en la negociación argumentando su acción pasada como garantía de éxito. ${ }^{28}$ Para las autoridades españolas, las negociaciones con grupos cimarrones no era algo fuera de lo común. Al igual que sucedió en los dominios caribeños de los británicos y holandeses, cuando las medidas coactivas y militares fracasaban, los procesos de negociación con las comunidades cimarronas eran viables. En las negociaciones que lograban culminar con éxito, las autoridades terminaban reconociendo, además de la libertad de los apalencados, el derecho a la explotación de la tierra, además de un amplio margen de autonomía política y jurisdiccional, como había sucedido a fines del siglo XVII en Santo Domingo con la fundación del pueblo de San Lorenzo de los Mina.

Si bien, en base a las declaraciones de los arrochelados y del Arzobispo de Santo Domingo, existía ya un grupo cimarrón con identidad definida a mediados del siglo XVIII, el sector más influyente y con mayor autoridad durante la negociación arribó a la parte española de la isla durante el gobierno de D. Manuel Azlor. Éste, al calor de los acuerdos alcanzados entre Francia y España en 1761, celebró un convenio con la colonia francesa, en 1762, cuya finalidad era encauzar vías para la colaboración en asuntos que fueran de mutuo interés, como la persecución de esclavos fugitivos. ${ }^{29} \mathrm{El}$ crecimiento del formidable edificio esclavista en Saint Domingue incrementó notablemente las tensiones de la sociedad de la colonia. El aumento del fenómeno del cimarronaje hasta mediados del siglo XVIII llevó a las autoridades francesas a mejorar e incrementar los sistemas de vigilancia, coacción, represión y búsqueda de esclavos fugitivos, con notable éxito. Así, para David Geggus, la implementación de esta política disminuyó considerablemente las posibilidades de los esclavos de huir de sus centros de trabajo, considerándolo como uno de los factores que podrían explicar la gran rebelión de $1791 . .^{30}$ Entre 1776 y 1777, las autoridades francesas financiaron y realizaron una gran expedición para destruir el maniel, si bien los resultados fueron calamitosos. ${ }^{31}$

Las acciones punitivas de Ázlor estuvieron condicionadas por las presiones francesas que pretendían erradicar el maniel. Pero al mismo tiempo, existieron motivaciones de carácter interno que incentivaron una política más decidida del gobernador dominicano. Azlor consideraba que los acuerdos diplomáticos con Francia debían ir acompañados de una serie de medidas que garantizaran el establecimiento de una frontera estable. Para ello, era necesario pacificar la zona y atraer población que pudiera colonizarla, ocupando el territorio y explotando los recursos naturales a su alcance, interponiendo una barrera infranqueable al avance francés. La colonización de la frontera, y la institucionalización de la población que pudiera asentarse en ella, eliminaba la posibilidad de que los franceses pudieran cruzar la frontera en acciones militares sin tener en cuenta a las autoridades dominicanas, como sucedió en 1761, cuando una expedición militar francesa trató de reducir de manera violenta el palenque. Si bien el intento terminó en un rotundo fracaso, dejó bien a las claras la actitud francesa hacia el problema, así como su capacidad para actuar de manera autónoma. Ante la imposibilidad de establecer de manera permanente una estructura de vigilancia, control y represión el cimarronaje, las autoridades españolas decidieron, de manera puntual, recurrir a acciones de tipo militar para destruir el palenque.

Las campañas hispano-francesas, comenzando por la realizada por el Gobernador español Azlor en 1768, y terminando por la realizada por 
Relación del diario de reconocimiento que pudo ser practicable en las sierras de Bauruco al sur de la villa de Neiba (10-15 de mayo de 1785), AGI. Santo Domingo 1102

33

Tratado definitivo entre España y Francia sobre límites en las posesiones en la isla de Santo Domingo. (Aranjuez 3 de junio de 1777). Archivo Histórico Nacional (en adelante AHN) Estado 3373, exp. 3.

34

Convención hecha por José Solano y el conde de Argous, comandantes generales en la Isla de La Española, del premio que reciprocamente había de exigirse por la prisión y el mantenimiento de los esclavos cimarrones en las montañas de Maniel y Bahoruco de la isla de Santo Domingo, cuya convención forma parte del tratado de policía celebrado entre España y Francia el 3 de junio de 1777 y fue firmada en Santo Domingo el 12 de junio de 1778 (AHN, Estado 3373, Expediente 6).

35

PINTO, Antonio. Una vecindad controvertida: Las relaciones bilaterales en La Española hasta 1795. Seminario de Investigación, Madrid, Departamento de Historia Contemporánea de la Universidad Complutense de Madrid, 25 de mayo de 2010, http://www.ucm.es/data/cont/media/ www/pag-13888/A_Jesus_Pinto.pdf

36

LIENHARD, Martin. 0p. Cit., p. 87-88.

37

RUPERT, Linda M. Marronage, Manumission and Maritime Trade in the Early Modern Caribbean. Slavery \& Abolition. Oxfordshire, 30, 3, 2009, p. 361-382.
Saint -Vilmé en 1777, si bien no consiguieron destruir el maniel, sí que tuvieron un profundo impacto en el mismo. Ante la presión militar, los cimarrones terminaron abandonando el territorio que hasta ese momento controlaban, buscando un lugar que les ofreciera mayores posibilidades de supervivencia, momento que fue aprovechado por las autoridades para quemar los recintos habitacionales en los que hasta ese momento moraban. Éste paraje abandonado, conocido años más tarde como el maniel viejo, estaba radicado a un día y medio de viaje de su posterior ubicación, en una zona montañosa de difícil acceso. ${ }^{32}$ Tras el abandono del maniel viejo se radicaron en la desembocadura del río Pedernales, lugar que les ofrecía la posibilidad

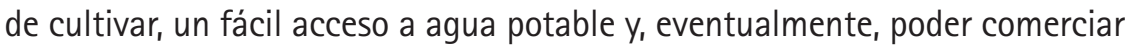
con las numerosas embarcaciones que frecuentaban la costa. Sin embargo, el lugar también ofrecía ciertas limitaciones para su defensa, por lo que fue abandonado en el año 1775, cuando regresaron nuevamente a las sierras de Neiba, estableciéndose en el territorio que detentaban cuando comenzaron las negociaciones para su reducción definitiva. La presión de las autoridades españolas se redobló en el año 1777, tras la firma de un tratado internacional con Francia para la devolución de cimarrones. ${ }^{33}$ Como aditamento al Tratado de Aranjuez, que incluía un apartado sobre policía y buen gobierno de las dos colonias, se dispuso que para acabar con los esclavos que estaban radicados en las montañas de Bahoruco, las dos monarquías se comprometían a redoblar sus esfuerzos organizando batidas en la zona fronteriza. Los cimarrones que pudieran capturar serían entregados a las autoridades de justicia de cualquiera de las dos colonias quedando transitoriamente en depósito, a la espera de que pudieran ser reclamados por sus dueños. Mientras se producía la reclamación, y durante un periodo máximo de un año, los esclavos podian ser dedicados al trabajo en obras públicas. De no producirse ninguna reclamación en el periodo de un año, los esclavos pasarian a propiedad de la Monarquía que los hubiera apresado, quedando expuesto el cimarrón a la normativa de la nación que lo aprendiera, tanto en materia penal como en asuntos relativos a su posible acceso a la libertad. ${ }^{34}$

El excelente clima diplomático entre las dos dinastías Borbónicas favoreció un marco de entendimiento de carácter político, en el que las relaciones entre Saint Domingue y Santo Domingo jugaban un papel preferente. Las autoridades españolas decidieron ofrecer recompensas a todos los civiles que pudieran capturar y llevar ante las autoridades de justicia a cualquier esclavo fugado, especialmente a los radicados en las serranías de Neiba. ${ }^{35}$ Sin embargo, la creciente presión militar no alcanzó los frutos esperados, y desde la colonia francesa, ya en 1782 , se comenzó a plantear la necesidad de un acuerdo que terminara por reconocer la libertad a los habitantes del maniel, a cambio de que se instalasen en Saint Domingue. ${ }^{36}$ Sin embargo, la delegación franca no tenía un posicionamiento fuerte en la negociación dado que el maniel estaba radicado fuera de la soberanía francesa, lo que vendría a confirmar que los cimarrones tenían una compresión altamente sofisticada de la complejidad de los diferentes marcos políticos y legales de las dos colonias, interpretándolos a su favor. ${ }^{37}$

La ubicación territorial definitiva del maniel respondió a sus necesidades defensivas. Además de constituirse en una zona alejada tanto de las autoridades coloniales como de vecinos, estaba situado al final de un pequeño camino, angosto, con escasa vegetación y casi sin agua, lo que dificultaba el abastecimiento y alimentación de cualquier expedición que pudiera armarse contra ellos. La entrada estaba situada en el extremo de 
LA ROSA CORZO, Gabino. Armas y tácticas de los cimarrones en Cuba. Reporte de investigación, La Habana, №2, Instituto de Ciencias Históricas, Academia de la Historia, 1989.

39

Informe del Capitán de Buscadores D. José Antonio de Rosas (Neiba, 17 de julio de 1785), AGI, Santo Domingo 1102

40

HERNÁNDEZ DE LARA, Odlanyer; RODRÍGUEZ TÁPANES, Boris y ARREDONDO ANTUNES, Carlos. Esclavos y cimarrones en Cuba: Arqueología Histórica en La Cueva del Grillete. Buenos Aires: Aspha Editores, 2014, p. 124. La cercanía de los cultivos a los lugares de residencia se debía a razones de seguridad.

LAVIÑA GÓMEZ, Francisco Javier. Alimentación y cimarronaje en Vuelta Abajo. Notas sobre e diario de un Rancheador. Barcelona: Boletín Americanista, 37, 1988. p. 203-214.

42

Informe de D. Juan de Bobadilla (Neiba, 8 de diciembre de 1790), AGI Santo Domingo 1102.

43

SÁNCHEZ VALVERDE, Antonio. Idea del Valor de la Isla Española y utilidades que de ella puede sacar su Monarquía. Madrid: Imprenta de D. Pedro Marín, 1785

44

Declaración de José Payano (Santo Domingo, 26 de agosto de 1790), AGI Santo Domingo 1102. Estos alzados eran "Bartolo Montesino, Carlos de la Peña un moreno que dice que es de la ciudad de Santiago, Manuel Moreta, de esta vecindad, José Corso, que dice ser de la ciudad de Maracaibo, Andrés Arieta, que dice ser de la misma ciudad, , Clemente Rosado, de la ciudad de Puerto Rico, Juan Ignacio, de la misma ciudad, Miguel Bonilla, de Maracaibo, Juan Francisco Balbuena, de la misma ciudad, Pedro Bocatuerta, un mulato de la ciudad de Cartagena, Diego Carrasco de este vecindario, Eusebio Fermín mulato de la ciudad de Santiago, Domingo Cabello alias judía copada, un indio del que ignora el nombre y un viejo que Ilaman Manuel Gallinas".

45

ZEUSKE, Michael. Saint Domingue en Cuba: El levantamiento en Banes el 13-14 de agosto de 1833. In: CWICK, Christian; LAVIÑA, Francisco Javier; ZEUSKE, Michael (eds.), Esclavitud, huida y resistencia en Cuba. Berlín: Wissenschaftlicher, Verlag, 2013. p. 139-181. una cuesta con una elevada pendiente, al final de la cual se abria el valle donde estaban radicadas la mayor parte de las viviendas. El valle estaba coronado por una serie de montes de gran altura, donde, en la cima de uno de ellos cerca de la entrada al valle, tenía su ubicación un vigía que velaba por la seguridad. La Rosa Corzo señala, en su estudio sobre los palenques cubanos, que la zona de vigía, además, servía como centro de aprovisionamiento de armas, por lo que su disposición en la cercanía de la entrada del maniel, no muy lejos del recinto habitacional, respondía a la lógica de maximizar los recursos a su alcance para mejorar su capacidad defensiva en caso de ataque. ${ }^{38}$

La disposición de las viviendas, era algo irregular, ubicadas a muy poca distancia unas de otras (todo el recinto habitacional constituido por 42 ranchos, quedaba constreñido a una distancia equivalente a un tiro de fusil), en torno a las faldas de la ladera de la montaña donde estaba ubicado el vigía, lo que ofrecía una disposición en hemiciclo. Ladrón de Guevera, comisionado en el maniel para conseguir su reducción en 1785, no observó ninguna construcción defensiva, en buena medida, porque las que ofrecía el paraje natural eran lo suficientemente importantes. No existía un lugar de aguada próximo a las viviendas, debiendo realizarse ésta en un estanque situado al fondo de una cañada. Como medio para optimizar los recursos, y ante eventuales dificultades de abastecimiento, los habitantes del maniel habían dispuesto la ubicación de un número importante de canoas con la finalidad de recoger toda el agua de Iluvia posible. El terreno estaba salpicado de diferentes sementeras de batata, plátanos y cañas, que constituían, junto al producto de la caza (la pieza más capturada era el cerdo cimarrón) la principal fuente de alimentación de los apalencados. El Capitán de Buscadores D. José Antonio de Rosas, que pasó 24 días en el maniel, llegó a describir la comida que le sirvieron, señalando que era una masa de batata rallada sin sal, que envuelta en hoja de plátano, se la dejaba cocer en las brasas candentes de las hogueras. ${ }^{39}$ Las sementeras, radicadas en las cercanías de los recintos habitacionales, ${ }^{40}$ estaban bajo responsabilidad de cada uno de los grupos familiares que constituian el maniel, y su extensión y capacidad era muy semejante, si bien observamos ciertas diferencias que podian sugerir un diferente status social entre sus propietarios. ${ }^{41}$ En cualquier caso, lo que parece indudable es la conformación de unidades familiares campesinas al interior del maniel cuya limitada producción satisfacía, hasta cierto punto, la demanda alimentaria de sus pobladores.

El precario excedente de su producción agrícola y de la caza era orientado al comercio con el exterior, con hatos ganaderos cercanos, con vecinos de la ciudad de Neiba, ${ }^{42}$ con esclavos que trabajaban de manera dispersa en el agro, ${ }^{43}$ o con un grupo de personas radicadas en la costa (Ilamados por las autoridades españolas como los alzados del Petitrout) que, al margen de las leyes coloniales, se dedicaban a la caza por los montes, el corte de maderas de caoba y la depredación de las costas. Estos, habían establecido un fluido contacto, gracias a la complicidad de algunos agentes españoles, con la ciudad de Jacmel. ${ }^{44}$ Los alzados eran excelentes intermediarios comerciales para los arrochelados, y les surtían, entre otros productos, de armas, pólvora y otros bastimentos indispensables para su supervivencia. La relación comercial favoreció su aceptación dentro del grupo cimarrón, donde encontraban cobijo, suministros e incluso interrelaciones de tipo personal, siendo frecuente el amancebamiento con mujeres del maniel. ${ }^{45}$ Por todo ello, las autoridades coloniales los percibían como un 
46

GOMES, Flavio. A hidra e os pântanos. Mocambos, quilombos e comunidades de fugitivos no Brasil (séculos XVII-XIX). São Paulo: Editora UNESP, 2005. p. 37-38.

47

CURTIS, Isaac. Masterless People: Maroons, Pirates and Commoners. In: PALMIE, Stephan and SCARANO, Francisco (eds.), The Caribbean. A History of the Region and its People. Chicago: The University of Chicago Press, 2011. p. 151.

48

Informe de los comisionados en el maniel (Neiba, 15 de mayo de 1785), AGI Santo Domingo 1102.

Entrevista de D. Luis de Chaves y Mr Demarates con Papa Pioró (Neiba, 15 de mayo de 1785), AGI, Santo Domingo 1102. claro peligro para el orden colonial, ya que no sólo vivían "alejados de las leyes de Dios y de los hombres", sino que habian favorecido que la región se convirtiera en un nido de contrabandistas, posibilitando además, la supervivencia de la comunidad cimarrona. La conexión comercial del maniel con el entorno y con el ámbito social en el que se desarrollaba estableció las bases para conectar al maniel ${ }^{46}$, de manera indirecta, con circuitos económicos más amplios de las sociedades coloniales a ambos lados de la frontera. ${ }^{47}$

En cuanto al número de pobladores, el censo elaborado durante su reducción establece un total de 133 habitantes, número sorprendentemente bajo que llamó la atención de las autoridades españolas. Los informes previos a la llegada de la comisión calculaban su número en torno a los 300 individuos, por lo que las autoridades españolas cuestionaron la veracidad de las cifras ofrecidas por los cimarrones. Sin embargo, estos, en boca de uno de sus líderes, señalaban que el maniel había visto reducido sensiblemente el número de sus habitantes, ya que las campañas militares efectuadas en su contra por el gobernador Azlor, así como una serie de epidemias, habían reducido sensiblemente el número de moradores. ${ }^{48}$ Sin embargo, debemos hacer notar que los cimarrones que aceptaron ser censados fueron aquellos que veían en la negociación una posible salida que podia legitimar su presencia en suelo dominicano, y que depositaban cierta confianza en las autoridades españolas. Esta opinión no era compartida por todos los habitantes del maniel, especialmente por aquellos cuya integración en la comunidad cimarrona era reciente, por lo que posiblemente, no todos los componentes del grupo estuvieron presentes en el censo. Además, pese a los compromisos adquiridos por los arrochelados, estos siguieron acogiendo esclavos fugados que no eran expuestos a las miradas de las autoridades por tratarse de una violación de los acuerdos alcanzados.

El padrón efectuado por las autoridades españoles muestra la existencia de cierta paridad en cuanto al sexo de los cimarrones, en edades no muy elevadas, donde se habían articulado unidades familiares que habían tenido descendencia. Según la explicación ofrecida por los arrochelados, la mayor parte conformaban familias por la imposición de los propios líderes políticos del palenque, ya que obligaban a todos los hombres que llegasen a su territorio en calidad de cimarrones a "tomar una negra y establecerse en un rancho".49 Si bien es posible que se tomaran este tipo de decisiones en base a lógicas políticas con las que pretendian conseguir ciertos grados de estabilidad, entendida ésta de una manera amplia, lo cierto es que el maniel, en base a los datos del censo, estaba compuesto principalmente por familias de tipo monoparental, con una gran presencia de niños, lo que vendría a confirmar la reconfiguración de ciertos tipos de familia tras el paso por la experiencia de la esclavitud. 0 , si los datos se ajustan principalmente, a los arrochelados dispuestos a negociar con las autoridades, podriamos establecer que una de las posibles motivaciones para tratar de llegar a un entendimiento con las autoridades coloniales dominicanas era la preservación de las unidades familiares que se habian constituido. 
Gráfico 1. Edades de los cimarrones varones en el maniel de bahoruco, 1785

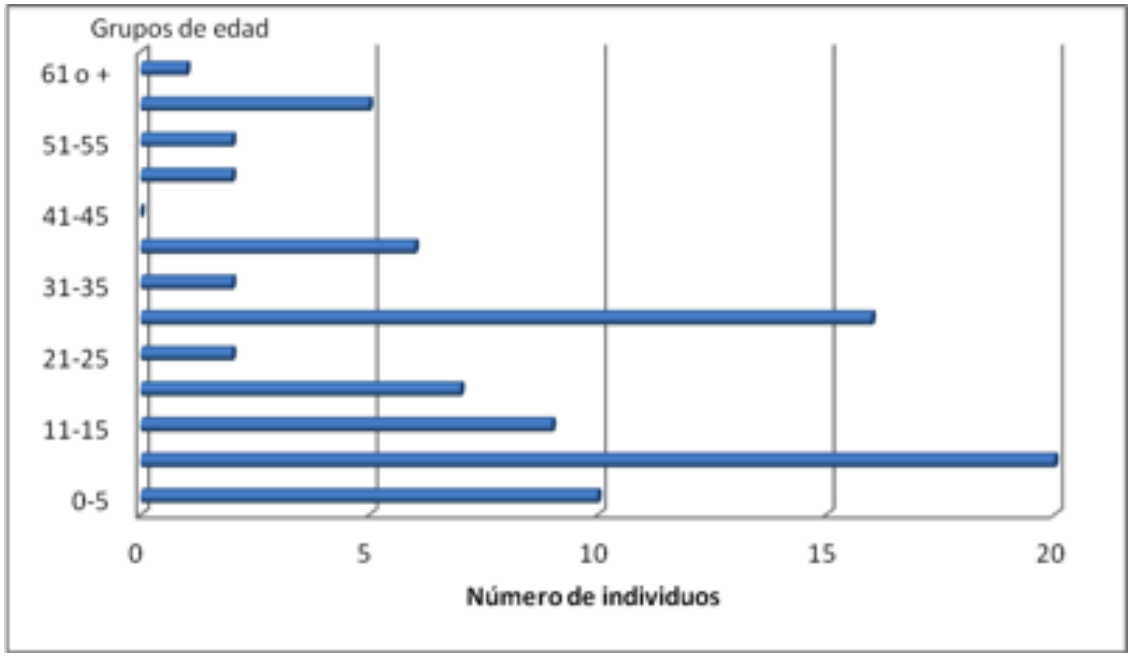

Fuente: Elaboración propia. AGI Santo Domingo 1102

Gráfico 2. Edades de las mujeres cimarronas en el maniel de bahoruco, 1785

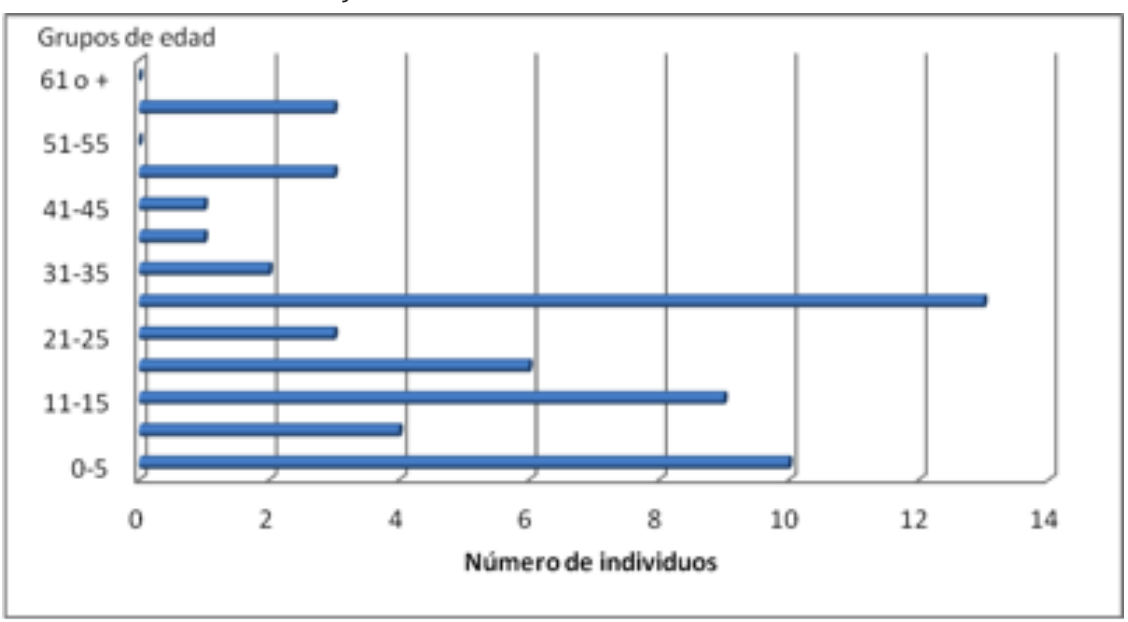

Fuente: Elaboración propia. AGI Santo Domingo 1102

Gráfico 3. Edades, sin antender al sexo, de los cimarrones del maniel, 1785

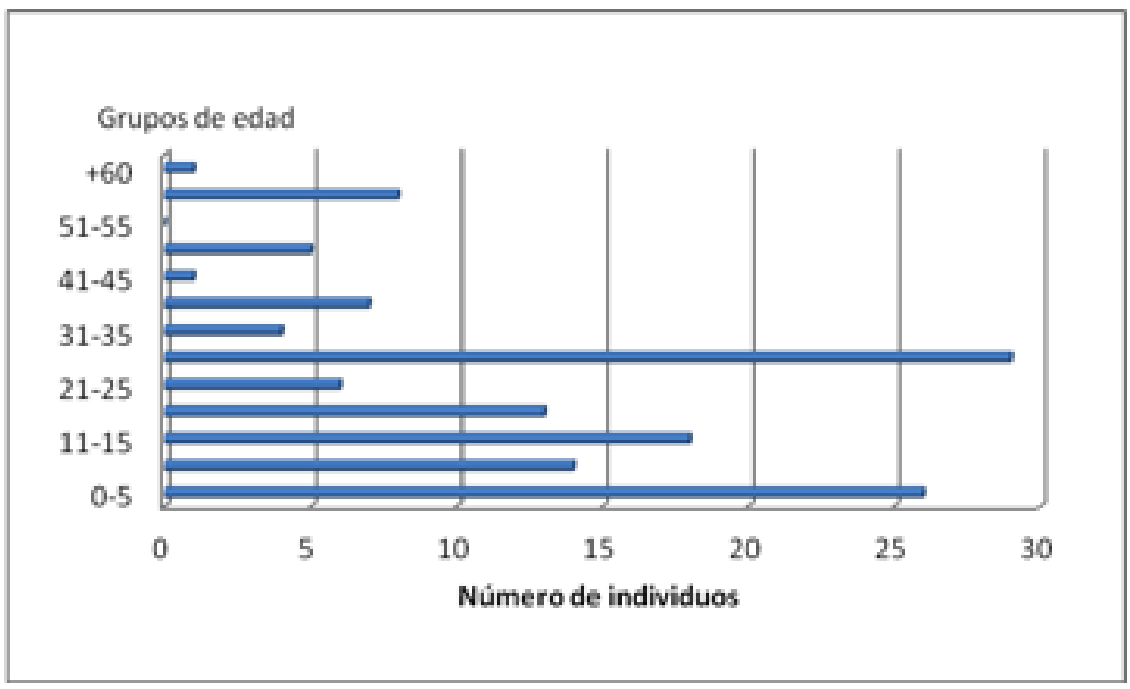

Fuente: Elaboración propia. AGI Santo Domingo 1102

La instalación de los arrochelados en Saint Domingue en un pueblo con la consideración de hombres libres y con acceso al cultivo de la tierra, estaba intimamente relacionada con el reconocimiento de facto de su 
Carta del embajador de Francia al Conde de Floridablanca (Madrid, 5 de septiembre de 1786), AGI Santo Domingo 1102.

51

Los diferentes intereses que entraban en juego en los intentos de reducción de eslavos cimarrones facilitaban que, con frecuencia, distintas instituciones coloniales tuvieran visiones opuestas en la estrategia a seguir. BENEI Véronique. The Corsair, the Bishop, the Governor and the runaways: Negotiating slavery in early eighteenth century Santa Marta, New Granada. Nuevo Mundo Mundos Nuevos [En ligne], Débats, mis en ligne le 28 mars 2014, consultado el 3 de junio de 2014. URL : http://nuevomundo.revues. org/66547 ; DOI : 10.4000/nuevomundo.66547

52

SEVILLA SOLER, Rosario. Santo Domingo tierra de frontera, 1750-1800. Sevilla: Escuela de Estudios Hispanoamericanos, 1980. p 81-87.

53

Testimonio de la diligencias obradas en consecuencia de la Real Cédula de 23 de mayo de éste año en el que el Rey autoriza al Arzobispo de Santo Domingo para el seguimiento de la reducción a vida sociable de los negros del maniel de Neiba (Santo Domingo, 9 de octubre de 1787), AGI Santo Domingo 1102.

54

GUTIÉRREZ ESCUDERO, Antonio. La estructura económica de Santo Domingo, 1500-1795. In: MOYA PONS, Frank (coord.). Historia de la República Dominicana. Madrid: Doce Calles, 2010. p. 92-93.

55

Testimonio de las diligencias obradas en consecuencia de la Real Cédula de 23 de mayo de este año en el que el Rey autoriza al Arzobispo de Santo Domingo, para el seguimiento en la reducción a vida sociable de los negros del maniel de Neiva (Santo Domingo, 9 de octubre de 1787), AGI Santo Domingo 1102.

56

PRICE, Richard. The miracle of Creolization: A Retrospective. New West Indian Guide. Leiden, vol. 75, No 1\&2, p. 35-64, 2001.

57

SCHWARTZ, Stuart B. Cantos and Quilombos. A Hausa Rebellion in Bahia, 1814. In: LANDERS, Jane G. and ROBINSON, Barry M. (eds.). Slaves, Subjects and Subversives: Blacks in Colonial Latin America. Albuquerque: University of New Mexico Press, 2006. p. 247-271.

58

BARCIA, Manuel. West African Islam in Colonial Cuba. Slavery Et Abolition, 0xford, 35:2 , 2014. p. 292-305.

59

REIS, João José. African Nations and Cultural Practices in Nineteenth - Century Salvador, Bahia. The 12th Annual Gilder Lehrman Center International Conference at Yale University. New Haven, 29-30 October, 2010, http://www.yale.edu/ glc/brazil/papers/reis-paper.pdf identidad colectiva. Los cimarrones sospechaban que las autoridades francesas estaban accediendo a la mayor parte de sus demandas con la única idea de re-esclavizarlos una vez hubieran traspasado la frontera, lo que provocó la ruptura de las negociaciones. En respuesta, la comisión francesa declaró nulo el indulto ofrecido y exigió al gobierno español la persecución y eliminación del maniel. ${ }^{50}$ Sin embargo, en Santo Domingo había opiniones encontradas en cuanto a la estrategia a seguir para la reducción ${ }^{51}$. El Arzobispo de Santo Domingo Fray Isidoro Rodríguez, favorable a la negociación pacífica, maniobró ante la corte sugiriendo que en adelante las negociaciones fueran encabezadas por D. Juan de Bobadilla, cura de Neiba, quien se había granjeado la confianza de los esclavos fugados. ${ }^{52}$ Desde la corte, el Monarca tomó la iniciativa, puso bajo su protección a los esclavos y ordenó que en adelante, las negociaciones fueran llevadas a cabo, exclusivamente, por los eclesiásticos, lo que indirectamente relegaba a un segundo plano a los franceses de las futura negociaciones..$^{53}$

Para las autoridades políticas dominicanas, la interferencia de los eclesiásticos resultaba intolerable, ya que la reducción era competencia del gobierno de la colonia y no de la Iglesia. Tanto el Gobernador como la Audiencia consideraban necesaria una política de mano dura contra los cimarrones. Desde su perspectiva, esta línea dura podía conseguir dos objetivos imprescindibles para el futuro de la colonia. De un lado, normalizar las relaciones con Saint Domingue, y de otro, ofrecer una imagen de dureza en consonancia con las diversas medidas que se estaban llevando a cabo en esos años para el fomento de la agricultura y por ende, del esclavismo. ${ }^{54}$ La conformación de una identidad, o mejor dicho, de una colectividad cimarrona en territorio dominicano, era contemplada como un factor de inestabilidad que podía suponer un grave obstáculo para el desarrollo del proyecto esclavista. En la apertura de una nueva ronda de negociaciones, la pugna por el liderazgo en las conversaciones generó constantes choques entre el arzobispado y el gobierno, si bien las disposiciones remitidas desde Madrid mantuvieron la primacía de los eclesiásticos para llevar a cabo la reducción. ${ }^{55}$

\section{Identidad, etnia y política}

La conformación y reconstrucción de identidades de los esclavos en América es uno de los tópicos que más bibliografía ha generado en los últimos años. En la actualidad, la discusión parece centrarse en la pervivencia o no de identidades africanas, sus transformaciones, así como el grado de criollización que, a lo largo del tiempo, estas comunidades presentaron. ${ }^{56}$ Para Schwartz, la creación de las identidades de los esclavos por parte de los esclavistas fue, en buena medida, un producto del sistema colonial, ya que si bien se crearon categorias especificas, éstas eran extraordinariamente simples ya que no contemplaban las divisiones políticas, culturales y religiosas de los diferentes grupos esclavizados. ${ }^{57}$ Sólo a medida que el siglo XIX fue avanzando, y los tratantes de esclavos pretendieron eludir la compra de etnias africanas concretas, la identificación étnico-cultural de los esclavizados fue haciéndose más concreta, ${ }^{58}$ eliminándose buena parte de las categorías "paraguas" que, hasta ese momento, servían para catalogar a los esclavos. ${ }^{59}$ Desde ésta óptica, los arrochelados del maniel vistos por las autoridades españolas o francesas podian presentar una imagen de cohesión e identidad colectiva en base al cimarronaje, que era real, y al mismo tiempo, imprecisa, ya que coexistían percepciones identitarias diversas, con jerarquías internas diferenciadas. Los esclavizados sufrieron 
60

GOMES, Flavio. Africanos, naciones y cofradias en Rio de Janeiro, siglos XVIII y XIX. Boletín Americanista, Barcelona, Año LXI, № 63, p. 173, 2011.

61

PAIVA, Eduardo França. Escravidão, dinâmicas de mestiçagens e o léxico ibero americano. Portuguese Journal of Political Science and International Relations, Braga, № 10, p.14, 2013.

62

HELLY, Denise, BARSKI, Robert y FOXEN, Patricia. Social Cohesion and Cultural Plurality. The Canadian Journal of Sociology, Vol. 28, № 1, Special Issue on Social Cohesion in Canada, Winter, p. 19-42, 2003.

63

ORTEGA, José G. Freedom, Identity and the Social History of Empire in Atlantic Cuba, 1795-1817, SlaveryctAbolition, Oxfordshire, Vol. 35, Issue 2, pp. 273-291, 2014.

64

MENDES QUEIROZ, Elisangela. Ao sul do fronteira cimarrón: 0 processo de redução dos negros do maniel de Neiba na llha de Espanhola (17821795). Disertación (maestrado en Historia Social). Facultad de Filosofia y Letras y Ciencias Humanas de la Universidad de São Paulo, São Paulo, 2012. p.93.

65

CIAPPARA, Frans. Religion, Kinship and Godparenthood as elements of Social Cohesion in Orendi, a late Eighteenth-Century Maltese Parish. Continuity and Change, Cambridge, Vol. 25, Special Issue 1, pp. 161-184, 2010.

66

BERLIN, Ira. From Creole to African: Atlantic Creoles and the Origins of African-American Society in Mainland North America. The William and Mary Quarterly, Williamsburg, Third Series Vol. LIII: 2, April, 1996, p. 251-253.

67

ZEUSKE, Michael. The Names of Slavery and Beyond: The Atlantic, The Americas and Cuba. In: SCHEMEIDER, Ulrike; FÜLLBERG-STOLBERG, Katja and ZEUSKE, Michael (eds.) The End of Slavery in Africa and the Americas. A Comparative Approach. Munster-Hamburg-Berlin-Wien-London: LITVerlag, 2011. p. 51-80.

68

SWEET, James. Recreating Africa. Culture, Kinship and Religion in the African Portuguese World 1441-1770. The University of North Carolina Press: Chapel Hill, 2003. p. 29-30.

69

0'TOOLE, Rachel. From the Rivers of Guinea to de Valleys of Peru. Becoming a Bran Diaspora within the Spanish Slavery. Social Text 92, Durham, Vol. 95, № 3, p. 19-36, Fall 2007. un permanente proceso de reorganización social y étnico, en el que signos, marcas y otra señales perdian, cambiaban o mantenían su significado originario, estableciéndose éste en función de sus condiciones de vida o el entorno social donde se desarrollase. ${ }^{60}$ Estas "dinámicas de mestizaje", desde una óptica esencialmente cultural, no deben entenderse sólo en base al resultado final, la existencia de una cultura mestiza, sino como el conjunto de fuerzas y operaciones que la hicieron posible. ${ }^{61}$ En el ámbito de una comunidad cimarrona cuyos componentes procedian de espacios culturales distintos y que habían vivido de manera disímil el proceso de esclavización y, posteriormente, el cimarronaje, afloraron diversas sensibilidades que afectaron a las negociaciones para la reducción. Si bien en un principio la conformación del maniel requirió de la participación de todos sus miembros y de la creación de mecanismos de solidaridad basados en la confianza para generar la cohesión social necesaria para su superviven$\mathrm{cia}_{1}{ }^{62}$ el desarrollo de las negociones con las autoridades generaron serias discrepancias entre los arrochelados, imposibilitando el establecimiento de un posicionamiento político único. ${ }^{63}$ La apertura de negociaciones de la comunidad cimarrona requería de diferentes esferas previas de negociación, siendo una de éstas la que se desarrollaba al interior de la propia colectividad. ${ }^{64}$ En este proceso, surgieron visiones casi antagónicas en cuanto a la actitud que debian mantener frente a las autoridades españolas y francesas, consecuencia de la heterogeneidad de la población cimarrona y de la incapacidad por establecer, de manera efectiva, los vínculos necesarios para dotar de cohesión a la totalidad del grupo. ${ }^{65}$

Para establecer las diferencias étnico-culturales de los cimarrones, en la medida en que la documentación lo permite, analizaremos los nombres con los que se identificaban los propios cimarrones en el censo practicado por los españoles. La imposición de nombres católicos y la eliminación de los nombres africanos suponía, en opinión de Ira Berlin, uno de los primeros pasos articulados por los compradores de esclavos para erradicar el pasado de los esclavizados. ${ }^{6}$ Éste proceso no se iniciaba en América, ya que en amplias regiones del costa occidental africana y de África Central, los esclavistas pretendieron eliminar cualquier pervivencia de los nombres de las personas que habían sido esclavizadas como parte del proceso que debía sumir en el olvido a la familia, a los dioses o clanes de procedencia. ${ }^{67}$ La creación de nombres quedaba habilitada especialmente en los territorios controlados por las potencias ibéricas y Francia, en base a su entrada en la fe católica. Sin embargo, el nombre católico, superpuesto a los nombres africanos, no implicaba necesariamente la eliminación o desaparición de éste último, aunque rara vez estos aparezcan escritos en la información oficial. En la práctica, la vida de muchos esclavos de origen africano estuvo determinada por la convivencia de dos planos, uno de carácter esencialmente africano, y otro de tipo colonial, en la que los esclavos podían convivir de manera contemporánea. Como señala Sweet para el caso brasileño, los esclavos africanos transformaron sus identidades a su llegada a América, articulando nuevas formas de relación, sin abandonar completamente la perspectiva africana. ${ }^{68}$ En este mismo sentido, Rachel 0'Toole incide en la persistencia cultural de diversos pueblos africanos en América, y cómo dicho bagaje cultural fue aprovechado y articulado por las personas esclavizadas en base a su conveniencia. ${ }^{69}$ Así, la detentación de los esclavos de identidades múltiples, si bien en un primer momento fue un producto de la violencia de la esclavización, pudo ser una herramienta utilizada e inter- 
ANDERSON, Richard; BORUCKI, Alex; DOMINGUES DA SILVA, Daniel; ELTIS, Davis; LACHANCE, Paul; MISEVIC, Philip and OJO, Olantuji. Using African Names to Identify the Origins of Captives in the Transatlantic Slaves Trade: Crowd-Sourcing and the Registers of Liberated Africans, 1808-1862". History in Africa, Cambridge, Available on CJO 2013, DOI:10.1017/ hia.2013.3

71

FICK, Carolyne. Making Haiti: Saint Domingue Revolution from below. Knoxville: University of Tennesse Press, 1990. p.26.

72

BERLIN, Ira. Op. cit., p. 254

73

LANDERS, Jane. Maroon Ethnicity and Identify in Ecuador, Colombia and Hispaniola. Conference paper delivered for the Latin American Studies Association, Miami, p.1-10, 2000. pretada por algunos esclavos en base a sus necesidades. Cuando se realizó el censo de los esclavos arrochelados en el año 1785, la inmensa mayoría de los mismos detentaban nombres franceses. A pesar de ello, encontramos con nombres que nos podrian acercar a las zonas originarias e incluso al grupo lingüístico al que podrian pertenecer, ya que existió una clara vinculación entre estos nombres africanos detentados por los esclavos y sus identidades etnoligüisticas. ${ }^{70}$

TABLA 1. Nombres africanos de los cimarrones del maniel, especificando la región de procedencia y el grupo lingüistico

\begin{tabular}{clc}
\hline NOMBRE & REGIÓN DE ÁFRICA & GRUPO LINGUISTICO \\
\hline GUMBA & ÁFRICA OCCIDENTAL & TIKAR \\
\hline DOSU & ÁFRICA OCCIDENTAL & YORUBA \\
\hline MUSANGA & ÁFRICA CENTRAL & KIKONGO \\
\hline MACUBA & ÁFRICA CENTRAL & BUSHOONG \\
\hline SAMBWE & ÁFRICA OCCIDENTAL & MANDE \\
\hline PEMBA & ÁFRICA CENTRAL & SWAHILI \\
\hline ZAMBA & ÁFRICA CENTRAL & KIKONGO \\
\hline SUANAR & ÁFRICA CENTRAL & LINGALA \\
\hline
\end{tabular}

Fuente: AGI Santo Domingo 1102 y http://african-origins.org/african-data/

Si bien el número de nombres africanos registrados es bajo, los datos señalan dos grandes regiones de procedencia, África Central y África occidental. Estos datos irian en consonancia con lo enunciado por Carolyn Fick, quien indica que los esclavos procedentes de estas regiones fueron demográficamente muy importantes en la colonia en el periodo inmediatamente anterior al comienzo de la revolución por el incremento del comercio de esclavos con esta zona desde $1773 .{ }^{71}$ En cualquier caso, la utilización de los nombres africanos en su relación con las autoridades fue minoritaria, y aplicados en ocasiones a niños que habían nacido en las sierras, lo que nos mostraría la persistencia de componentes culturales africanos transmitidos, principalmente, por los progenitores. ${ }^{72}$ Además, la llegada al maniel de esclavos nacidos en África escasamente aculturados posibilitaba, de manera más o menos fluida, aportaciones culturales continuadas. ${ }^{73}$

La utilización, por parte de los cimarrones, de los nombres con el que eran conocidos en el mundo colonial tenía una finalidad política. En un espacio donde podían pasar desapercibidos y presentarse con un nombre distinto, los cimarrones optaron por presentar sus nombres coloniales, ya que de éste modo podian ser identificados correctamente. La finalidad del censo, interpretada desde el punto de vista de los arrochelados, era precisamente su correcta identificación, ya que su objetivo político era conseguir el reconocimiento de su libertad. Si la identificación era errónea, o existían serias dudas sobre la misma, el cimarrón corría el riesgo de ser nuevamente esclavizado. Si se daban las circunstancias adecuadas, los esclavos podían adoptar identidades múltiples que podían ser utilizadas en base a su conveniencia, distinguiendo el entorno donde estuviera desen- 
LAVIÑA, Francisco Javier. Etnicidad y resistencia a la esclavitud. In: CWIK, Christian; LAVIÑA, Francisco Javier; ZEUSKE, Michael (eds.) Esclavitud, huida y resistencia en Cuba. Berlín: Wissenschaftlicher Verlag, 2013. p.15-30.

75

ZEUSKE, Michael. Hidden markers, open secrets: on naming, race-marking and race-making in Cuba. New West Indian Guide, Leiden, Vol. 76, № 3-4, p. 213, 2002.

76

Testimonio del expediente formado sobre la reducción de negros del maniel de Neiba (Neiba, 8 de abril de 1790), AGI Santo Domingo 1102.

77

Carta del Presidente de la Audiencia de Santo Domingo (Santo Domingo 10 de octubre de 1787), AGI Santo Domingo 1102.

78

VAN NORMAN, William. The Process of Cultural Change Among Cuban Bozales During the Nineteenth Century. The Americas, Berkeley, Vol. 62, № 2, p. 177-207, October 2005.

79

LOVEJOY, Paul. Comparación de la vida de dos musulmanes en América: Muhammad Kaba Saghanaghu y Mahommah Gardo Baquaqua. Estudios de Asia y África, México D.F., Vol XLIII, N 1, p. 13-32, Enero-Abril 2008.

80

BASTIDE, Roger. Continuidad y discontinuidad en las sociedades afroamericanas. In: CUNIN, Elisabeth (ed). Textos en diáspora. Una antología sobre afrodescendentes en América. Instituto Nacional de Antropología e Historia, México DF, p. 43-44, 2008.

81

Informe de los comisionados del maniel (Neiba, 12 de abril de 1785), AGI, Santo Domingo 1102. volviéndose, las personas o instituciones a las que se estuviera dirigiendo 0 la finalidad que pretendiera conseguir. ${ }^{74}$ La legitimación del status jurídico requería, por tanto, de la utilización por parte de los arrochelados de los instrumentos del sistema colonial, lo que incluía, necesariamente, su identificación en base a los parámetros coloniales. Por ello, la utilización de nombres africanos por parte de los mismos se refería, mayoritariamente, a los niños que habían nacido en las sierras y no a los esclavos que habian huido de sus propietarios. Estos niños no podían ser identificados por sus amos franceses, y heredarian la consideración jurídica de la madre, que era la persona que debía ser correctamente identificada por parte de las autoridades coloniales.

El maniel presentaba una serie de diferenciaciones identitarias que fue perceptible para las autoridades españolas y francesas a medida que el proceso de negociación fue avanzando. Si bien éstas sólo se centraban en aspectos superficiales, ${ }^{75}$ como su mayor o menor pertenencia, en tiempo, a la comunidad cimarrona, fueron instrumentalizadas por las autoridades para mejorar su posicionamiento en la mesa de negociaciones, empleando para ello una serie de estrategias encaminadas a conseguir bien el asentamiento de los cimarrones en un pueblo, ${ }^{76}$ o bien su reducción y posterior dispersión en diferentes poblaciones dominicanas. ${ }^{77}$ De las 133 personas censadas por las autoridades españolas, 131 confesaban haber escapado del Saint Domingue o ser sus descendientes. Las otra dos personas censadas manifestaban ser uno, holandés, probablemente procedente de las colonias neerlandesas del Caribe, y el otro español, procedente de Bánica, población fronteriza de Santo Domingo. Si bien existía una procedencia común mayoritaria, esto por sí mismo no tuvo una repercusión directa en la conformación de las identidades al interior de los apalencados. William Van Norman explicita que la conformación y los cambios de las identidades de los esclavos habria que entenderlas de una manera global, atendiendo a las formas de esclavización en África, el modo en el que se desarrollaba el viaje transatlántico y las formas de explotación a la que eran sometidos una vez llegados a América ${ }^{78}$. A pesar de la violencia del proceso de esclavización y al indudable impacto que tuvo en las personas esclavizadas, éstas tuvieron la capacidad para, en diferente medida, reconstruir instituciones sociales y políticas. ${ }^{79}$ En este sentido, su construcción identitaria fue compleja y evolutiva, debiendo establecerse al menos tres grandes fenómenos que actuaron de manera contemporánea para conformar identidades comunitarias diferenciadas; la diversidad étnico-cultural, la experiencia de la esclavitud, entendida en su forma más extensa y, por último, el periodo de tiempo que los esclavos habian vivido como cimarrones. ${ }^{80}$

A medida que los contactos negociadores se desarrollaron, fue claro para las autoridades la existencia de dos grupos, con liderazgos distintos, al interior de los apalencados. ${ }^{81}$ Si bien estamos de acuerdo con los postulados de Lienhard en tanto en cuanto considera que la distinción de estos grupos se basaba en la decisión política de negociar, o no, con las autoridades, consideramos que esta decisión política se debía, entre diversos factores, a su experiencia bajo la esclavitud y al modo de vida cimarrón. Cada uno de estos grupos tenía una agenda política diferenciada, que procedía de los propios cimarrones y que marcaban estrategias de negociación y objetivos particulares. De un lado, los autodefinidos como "criollos del maniel" o "criollos de la montaña" e incluso "criollos de la sierra" y de otro los bozales o "estampados". El primer grupo estaba compuesto, principalmente, 
82

GÓMES, Flavio. Etnogénesis y ocupación colonial: Africanos, indigenas, criollos y cimarrones en Brasil, siglo XVIII. Anuario IEHS, Tandil, 26, pp. 55-73, 2011.

83

BARTHÉLÉMY, Gerard. Le rôle des Bossales dans l'emergence d'une culture marronage en Haïti. Cahiers d'Études Africaines, Paris, Vol. 37, Cahier 148, La Caraïbe: Des îles au continent, p. 840, 1997.

84

THORNTON, John. I am subject of the King of Kongo: African Political Ideology and the Haitian Revolution. Journal of World History, Honolulu, Vol. 4, № 2, pp. 181-214, Fall - 1993.

85

MILLER, Joseph. Retention, Reinvention and Remembering: Restoring Identities through Enslavement in Africa and under Slavery in Brazil. CURTO, Jose and LOVEJOY, Paul (eds.). Enslaving Connections. Changing Cultures of Africa and Brazil during the Era of Slavery. Amherst, Humanity Books, 2004. p.86.

86

ARAUJO, Ana Lucia. Dahomey, Portugal and Bahia: King Adandozan and the Atlantic Slave Trade. Slavery \& Abolition. Oxford, 33, 1, 2012, p. 7.

87

MINTZ, Sidney. The Socio-Historical Background to Pidginization and Creolization. In: HYMES, Dell (ed.) Pidginization and Creolization of Languages: Proceedings of a Conference Held at the University of the West Indie. Cambridge: Cambridge University Press, 1974. p.491.

88

Entrevista de D. Luis de Chaves y Mr. Demarates con Papa Pioró (Neiba, 15 de mayo de 1785), AGI Santo Domingo 1102.

89

PESSOA DE CASTRO, Yeda. Lenguas africanas. Factor de resistencia en la ruta del esclavo. Del Caribe, Santiago del Cuba № 28, p.71-74, 1998. KOUASSI DENOS, Koffi. Raza y cultura negra en América Latina. Latinoamérica. Anuario de Estudios Latinoamericanos, Mexico DF, № 20, p. 68, 1989. por cimarrones que habían escapado de Saint Domingue durante el gobierno de Azlor, a fines de la década de los sesenta y los descendientes de los mismos. Era un grupo que llevaba al menos veinte años viviendo como cimarrones en diferentes emplazamientos, que había rechazado las sucesivas incursiones militares que lanzaron contra ellos tanto franceses como españoles, y que tenían un extraordinario conocimiento del territorio y de su entorno. Habian articulado unidades familiares, bien entre los miembros de este grupo o acogiendo a esclavos fugitivos del Saint Domingue. Poseían una estrecha vinculación con el territorio donde estaba radicada favoreció un proceso de "territorialización" de la comunidad cimarrona. ${ }^{82}$ La utilización por parte de esta facción del término "criollo" lo podemos considerar como un instrumento utilizado por los arrochelados para reclamar una serie de derechos en su intento por ser considerados más que cimarrones, colonos con derecho a la propiedad sobre las tierras donde se podrían ubicar. Una parte sustancial de su experiencia vital estaba mediatizada profundamente por su experiencia cimarrona, que, por su prolongación en el tiempo, había conformado lazos en base a las experiencias comunes que habian tenido que afrontar..$^{83}$ En un principio, su liderazgo estaba detentado por Santiago, cimarrón procedente de Bánica, en el Santo Domingo español. En opinión de Thornton, la comprensión de los liderazgos políticos entre la población esclavizada de origen africano se legitimaba en función de la capacidad que pudieran tener un individuo de satisfacer las necesidades de tipo comunitario, ${ }^{84}$ fenómeno que se daba con frecuencia entre las comunidades cimarronas en América. Además, la creación de estos liderazgos, con asiduidad, recaía en personas de edad avanzada, en buena medida por su capacidad de crear redes sociales a lo largo del tiempo. ${ }^{85}$ Al mismo tiempo, las personas mayores eran consideradas la memoria viva de muchas comunidades africanas $y_{1}$ como guardianes de la memoria, solian tener una ascendencia política importante por su capacidad de asesoramiento ${ }^{86}$. En el caso de Santiago, su jefatura se justificaba por dos cuestiones; la primera, por su edad (más de 50 años), lo que le otorgaba un cierto ascendiente entre los arrochelados en base a su experiencia, y en segundo lugar, por ser el único cimarrón que sabía hablar español. Si bien las autoridades españolas señalaban que la lengua franca de comunicación en el maniel era el francés, éste era hablado de manera disímil por los cimarrones, en función del grado de conocimiento del idioma y de la mezcla de vocablos africanos. ${ }^{87}$ En las ocasiones en las que Santiago no actuaba como negociador, las propias autoridades españolas confesaban tener ciertas dificultades de comunicación, porque en el mejor de los casos los arrochelados hablaban "un jergón francés entendible", ${ }^{88}$ el francés criollo utilizado por los esclavos en Saint Domingue. La imposición de la lengua del propietario, si bien era un proceso agresivo que pretendía de un lado erradicar patrones culturales africanos y de otro, que el propietario tuviera el grado de comunicación suficiente para extraer la mayor cantidad posible de trabajo del esclavo, también puede ser interpretado desde otro prisma. Dada la diversidad lingüística de la población esclavizada, el uso del idioma del propietario posibilitaba un mayor grado de comunicación, además de facilitar la comunicación con el entorno social en el que se encontraban. ${ }^{89}$ El manejo del español le otorgaba a Santiago una mayor capacidad para dirigirse y comunicarse con las autoridades dominicanas, erigiéndose en un mediador cultural imprescindible para la comunidad, que posibilitaba las interacciones sociales, económicas y políticas del maniel con el entorno. A 
90

FALL, Yoro. Historiografía, sociedades y conciencia histórica de África. In: DJOGBÉNOU, Adonon Fabien. Hacia el universo negroafricano. México D.F.: Universidad Nacional Autónoma de México, 2003. p. 109.

91

ATSÉ, Kimou. Op. Cit., p.93.

92

LA ROSA CORZO, Gabino. Tatuados. Deformaciones étnicas de los cimarrones en Cuba. La Habana: Fundación Fernando Ortíz, 2011. p. 34-40.

93

HALL, Gwendolyn Midlo. Slavery and African Ethnicities in the Americas. Chapel Hill: The University of North Carolina Press, 2005. p.32. 94

OJ0, Olatunji. Beyond Diversity: Women, Scarification and Yoruba Identity. History in Africa, Cambridge, 35, p. 347-374, 2008. medida que el tiempo de negociación fue pasando, y tal vez por la muerte de Santiago, el liderazgo de éste grupo pasó a una persona de su confianza, un cimarrón Ilamado Felipe. En el censo elaborado por los españoles en 1785, Felipe confesaba tener 30 años, estar casado con Margarita, también denominada como "criolla del maniel" y tenía dos hijas, llamadas Teresa (de quince años) y Úrsula (de ocho). En contraste con la utilización de nombres africanos para algunos infantes, Felipe y su esposa nombraron a sus hijos con nombres procedentes del santoral católico, lo que nos remite a la cuestión sobre la búsqueda de la inserción formal de los "criollos del maniel" dentro de la sociedad colonial dominicana.

El segundo grupo estaba conformado por esclavos recién llegados al maniel procedentes del Saint Domingue, posiblemente la mayor parte de los mismos nacidos en África, pero, lo que creemos como más determinante, con un periodo de vida como fugitivos sensiblemente menor que el del grupo de "criollos del maniel". Las autoridades españolas los denominaban de manera genérica "bozales", pero que se autodenominaban así mismos como "estampados". La auto-definición del grupo hacía referencia al proceso de carimba, la marca de fuego, al que habian sido sometidos a su llegada a la colonia francesa. Éste proceso era uno de los primeros elementos que pretendían imponer, simbólicamente, el dominio de los propietarios sobre los cuerpos esclavizados. En buena medida, por la extraordinaria significación que, en muchas culturas africanas, tenía la piel, como registro visible de las experiencias vitales y como guardiana de las identidades culturales. Como sugiere Yoro Fall, muchos pueblos africanos desarrollaron sistemas gráficos, no necesariamente equivalentes a la escritura europea, que fueron utilizados conscientemente para describir el mundo y relatar sus historias. ${ }^{90}$ Las marcas en la piel, o la utilización de escarificaciones, servían como vehículo de comunicación, conformándose el cuerpo en portador de mensajes. ${ }^{91}$ Como sostiene La Rosa Corzo, el uso de tatuajes entre los esclavos y los cimarrones en Cuba formaba parte de un sistema de comunicación e identificación, que ofrecía información sobre género, clanes, linajes, tribus y filiación cultural, así como información sobre la categoría social del individuo o ritos de paso superados..$^{92}$

La utilización de tatuajes o marcas en la piel conoció grandes cambios en la costa occidental africana a lo largo de la centuria ilustrada. En territorio Yoruba, el estado de guerra casi generalizado desde finales del siglo XVIII, provocó fuertes movimientos migratorios. La diáspora yoruba al interior del continente africano generó que diferentes grupos étnicos entraran en contacto entre sí, estableciéndose mezclas culturales complejas. ${ }^{93}$ En éste proceso, las fronteras culturales de los diferentes grupos se difuminaron, permitiendo la adopción de ciertas costumbres, como las escarificaciones o los tatuajes, en pueblos que hasta ese momento no lo habían usado. ${ }^{94}$ Así, una parte importante de los esclavos que llegaban de África en este periodo, estaban más que familiarizados con las marcas en la piel, con la consideración del cuerpo como herramienta de transmisión de información, las utilizaran ellos mismos o no. Por ello, si bien los esclavistas pretendieron imponer un símbolo corporal, visible, que delatara y clasificara a los esclavos recién llegados a América, los propios esclavos eligieron éste símbolo para definirse. Si bien la incidencia de los tatuajes o de las escarificaciones era disímil en las diferentes culturas africanas, la marca de fuego impuesta por los esclavistas era común a todos ellos, por lo que la elección de éste símbolo como factor de auto-identificación no era 
96

REID, Michelle. The Yoruba in Cuba. Origins, Identities and Transformations. In: FALOLA, Toyin and CHILD, Matt D. (eds). The Yoruba Diaspora in the Atlantic World. Bloomington: Indiana University Press, 2004. p.116-117.

97

GEGGUS, David. Haitian Revolutionary Studies. Bloomington: Indiana University Press, 2002. p.72.

98

DUBOIS, Laurent. Avengers of the New World. The Story of Haitian Revolution. Cambridge: The Belknap Press of Harvard University Press, 2004. p. 184.

99

BARCIA, Manuel. West African Warfare in Bahia and Cuba: Soldier Slaves in the Atlantic World 1807-1844. 0xford: Oxford University Press, 2014. p. 132.

100

GEGGUS, David Patrick, Sugar and Coffee Cultivation in Saint Domingue and the Shaping of the Slave Labor Force. In: BERLIN, Ira and MORGAN, Philip. Cultivation and Culture: Labor and the Shaping of Slave Life in the Americas. Charlottesville: University of Virginia Press, 1993. p.80-81. casual y tenía una clara connotación política. ${ }^{95}$ Estariamos ante un procedimiento de re-significación de signos y símbolos, donde la experiencia cercana de la esclavitud, más que la forma de vida cimarrona, conformó la identidad del grupo, utilizando como vehículo de expresión las tradiciones africanas que habilitaban al individuo, o a su piel, como una fuente de la memoria vital. En buena medida porque la esclavitud, caracterizada por un sistema brutal de explotación laboral, en un entorno cultural distinto y extraordinariamente agresivo, tuvo un impacto decisivo en la conformación de la identidad de este grupo. ${ }^{96}$ En opinión de David Geggus, este grupo contó con cierta movilidad a lo largo del espacio fronterizo, y o bien tenían relaciones bastante fluidas con comunidades cimarronas del lado francés, o bien tenían basamento en Saint Domingue, donde en eran conocidos por las autoridades francesas como la comunidad cimarrona de Doco. ${ }^{97}$ Laurent Dubois señaló que ésta comunidad cimarrona poseía una fuerte cohesión internada, detectando la presencia de grupos ararás escasamente ladinizados que mantenían aún su lengua originaria como vehículo de comunicación. ${ }^{98}$ Este factor nos lleva a plantear, como hace Manuel Barcia, que el factor étnico podía ser determinante a la hora de conformar formas estructuradas de resistencia de tipo colectivo. ${ }^{99}$ La cohesión de los Doco podía verse facilitada por las variaciones regionales en cuanto a la composición étnica de los esclavos en Saint Domingue. La diversidad de las plantaciones en las tres provincias de la colonia, con distintos cultivos predominantes, tenía incidencia en la conformación étnica de las dotaciones de esclavos, en las que predominaban los esclavos nacidos en África. Los plantadores de café adquirian, principalmente, esclavos vivis, mandingas, igbos y congos, mientras que los esclavos procedentes de la bahía de Benín se podian encontrar, en mayor proporción, en las plantaciones de azúcar. ${ }^{100} \mathrm{Si}$ aceptamos la sugerencia de Geggus, en tanto a la relación de los "estampados" con los Doco, que contaban con una importante presencia de esclavos ararás, cabria preguntarse, hasta qué punto, existía un grado de cohesión étnica entre el grupo de los estampados, al modelo de la comunidad cimarrona del Saint Domingue. Y más relevante aún si lo contraponemos con los nombres africanos recogidos del censo de pobladores del maniel, que mostraba una fuerte presencia, al menos desde el punto de vista cultural, de esclavos procedentes de África central; ¿Hasta qué punto la heterogeneidad de grupos africanos en el maniel incidió en la conformación de grupos distintos y de políticas diferenciadas en cuanto a la negociación con las autoridades coloniales? Infelizmente, no disponemos de más datos para confirmar o refutar la cuestión, en tanto la documentación no arroja más información. En cualquier caso, lo que sí podemos confirmar es que ambos grupos tuvieron una experiencia disímil bajo la esclavitud y durante el periodo en el que vivieron como cimarrones, lo que sin duda debió incidir en la conformación de identidades y en la posterior toma de decisiones políticas al interior del maniel.

Al igual que sucedía entre los "criollos del maniel", estaban liderados al inicio del proceso de negociación por un esclavo de edad avanzada, y su actitud hacia las autoridades francesas y españolas fue menos receptiva a la negociación. Sin embargo, en poco tiempo, el liderazgo recayó en un cimarrón conocido como La Fortune, que no aparece recogido en el censo, que endureció aún más la posición negociadora, evitando con dilaciones y negativas la posibilidad del diálogo. Ésta actitud podía ser interpretada en base al cercano recuerdo de la esclavitud, a la escasa confianza 
101

THORNTON, John. African Dimensions of the Stono Rebellion. The American Historical Review Oxfordshire, Vol.96, №4, pp. 1101-1113, October 1991. MOSER, Bruce. Rebellion, Marronage and Jihad. Estrategies of Resistance to Slavery on the Sierra Leone Coast. Journal of African History, Cambridge, 48, p. 27-44, 2007.

102

Carta de Vicente Tudela al Capitán General D. Manuel González (Neiba, 9 de septiembre de 1787), AGI Santo Domingo 947.

103

El Arzobispo de Santo Domingo pide que se le deje actuar sólo con total independencia de la Audiencia y de cualquier otra persona para el final feliz de la reducción (Santo Domingo, 24 de diciembre de 1787), AGI, Santo Domingo 1102.

104

Real Cédula de 12 de diciembre de 1788 relativa a reducir a la vida civil a los negros del maniel, AGI, Santo Domingo 1102.

105

Testimonio sobre el expediente formado sobre el cumplimiento de la Real Cédula sobre la reducción de los negros del maniel (Santo Domingo, 19 de septiembre de 1789), AGI, Santo Domingo 1102.

106

Testimonio de D. Juan de Bobadilla y del Teniente del Batallón veterano de Santo Domingo D. Lorenzo Nuñez sobre la reducción de los negros del maniel, (Neiba, 5 de mayo de 1790), AGI, Santo Domingo 1102

\section{7}

Carta de D. Lorenzo Nuñez a D. Joaquín García (Santo Domingo, 21 de agosto de 1791) AGI, Santo Domingo 954.

\section{8}

Carta al Arzobispo de Santo Domingo (San Lorenzo de El Escorial, 18 de diciembre de 1792), AGI, Santo Domingo 1102.

\section{9}

Visita pastoral hecha a la nueva población de El Naranjo (Santo Domingo, 3 de junio de 1794) AGI, Santo Domingo 1102

110

PAIVA, Eduardo França. Allah and the New World: Slaves and Free Islamized in the American Colonial Universe. In: Elisabeth Herrmann-Otto; Marcel Simonis; Alexander Trefz. (Org.). Sklaverei und Zwangsarbeit zwischen Akzeptanz und Widerstand. Hildesheim: Georg Olms Verlag, 2011. pp. 281-308.

111

GÓMEZ, Pablo F. The Circulation of Bodily Knowlodge in the Seventeenth-Century Black Spanish Caribbean. Social History of Medicine, Oxford, Vol. 26, № 3, p. 383-402, 2013. que pudieran depositar los arrochelados en las autoridades coloniales, a experiencias africanas previas 0 a la suma de todos éstos factores. ${ }^{101} \mathrm{La}$ ruptura de las negociaciones descrita al inicio de este trabajo provocó que los arrochelados empezaran a acoger nuevamente a cimarrones fugados de Saint Domingue, ${ }^{102}$ cuyas autoridades pusieron precio a la cabeza de Lafortune, aunque no tuvieron éxito en su intento de capturar o matar al líder cimarrón. ${ }^{103}$

\section{La reducción en marcha}

a pesar de las reticencias iniciales, y en contra de la opinión de las autoridades francesas y de la Audiencia de Santo Domingo, la acción del Arzobispo y del cura Juan de Bobadilla comenzó a dar sus frutos. Con el apoyo del monarca, que redactó una Real Cédula en la que se ofrecía un indulto general a todos los habitantes del maniel, reconociéndoles como libres con derecho a la propiedad de tierras para su asentamiento y labranzas, los contactos con los criollos del maniel se intensificaron. La contraprestación que se exigía a los cimarrones era su compromiso de no aceptar más esclavos fugados, realizar labores periódicas de captura de otros esclavos cimarrones por cuya entrega serian remunerados y vigilar la frontera. ${ }^{104} \mathrm{~A}$ pesar de los dictámenes negativos de la Presidencia de la Audiencia, que alertaban del incumplimiento de las responsabilidades por partes de los arrochelados, ${ }^{105}$ la acción del Arzobispo fue decidida y, tras largas deliberaciones, impulsó la edificación de unos bohíos en un paraje denominado El Naranjo, en las cercanías de la villa de Neiba. ${ }^{106}$ La construcción de dicho asentamiento estuvo en manos de los "criollos del maniel" que sufragaban en parte su mantenimiento, y que comenzaron a instalarse en el lugar de manera gradual. El proceso de edificación fue lento, ya que, al margen de las disputas por la reducción en el interior del maniel, éste se vio afectado por una epidemia de viruela que afectó a buena parte de sus miembros. ${ }^{107}$ Finalmente, a últimos de 1792 se constató que a la edificación de los bohíos había seguido el asentamiento de los criollos. ${ }^{108}$ Sin embargo, el Arzobispo mostraba gran preocupación por la posibilidad de que no se pudiera traer al orden civil a los arrochelados radicados en el Naranjo. Por ello, en una visita pastoral realizada a la población recomendaba al cura doctrinero que observara "las acciones y palabras de los negros, cuanto puedan mixturar de superstición y vana observancia, como en modos y posturas superfluas para matar a los animales que han de comer, acciones previas e inútiles para el uso de la bebida, entrada y salida de sus casas, vestir nueva ropa, observación del canto y vuelo de las aves (...) se les debe enseñar la lengua castellana, porque no la habla nadie, ni siquiera los más jóvenes (...)". ${ }^{109} \mathrm{~A}$ través de las advertencias del eclesiástico podemos percibir la persistencia de un número importante de tradiciones alejadas del cristianismo que hundían sus raices en las diferentes culturas africanas de origen, o de ciertos caracteres islamizantes, que eran recreados con cierta frecuencia en los espacios americanos. ${ }^{110}$ Pero además, como señala Pablo F. Gómez, la imbricación de los portadores de saberes religiosos o médicos, con la conformación de liderazgos políticos entre la población esclavizada o libre del Caribe hispánico, estaba plenamente establecida desde al menos el siglo XVII. ${ }^{111} \mathrm{El}$ establecimiento de la ortodoxia religiosa cristiana, además de perseguir un objetivo piadoso, tenía un trasfondo político, ya que trataba de limitar la emergencia de liderazgos desde el interior de estos grupos. 
112

Bando para que cese el uso de dar la libertad a los esclavos procedentes de las colonias extranjeras que llegaran a aquella isla (Santo Domingo, 17 de mayo de 1790), AGI, Santo Domingo 953.

113

Representación del Fiscal de la Audiencia al Comandante de las Armas de Neiba (Santo Domingo, 31 de agosto de 1790), AGI, Santo Domingo 1102.

114

El Gobernador de Santo Domingo participa el ningún fruto que ofrecen los comisionados en el maniel de Neiba, (Santo Domingo, 16 de septiembre de 1791) AGI, Santo Domingo 954. "Cumplidos los vaticinios de este gobierno formados sobre el conocimiento del dolo, inconstancia e insubordinación de aquellos alzados, y los fundados recelos de otros inmediatos y mas funestos en la posteridad, por el abrigo de nuevo número de bozales y su ocultación en parajes de seguridad, y bajo de unas cautelas maliciosas con los auspicios de algunos mulatos de la colonia francesa colindante con la nuestra".

115

JAUREGUI, Carlos. El negro comegente: Terror, colonialismo y etno-politica. Afro-Hispanic Review, Nashville, Vol. 28, №1, p.54, Spring, 2009.

116

Carta de D. Vicente Tudela ( Neiba, 29 de enero de 1791) AGI, Santo Domingo 1102.

117

Carta al Arzobispo de Santo Domingo (San Lorenzo de El Escorial, 18 de diciembre de 1792), AGI, Santo Domingo 1102

118

Informe de los comisionados del maniel a D. Joaquín Garcia (Neiba, 8 de agosto de 1791), AGI, Santo Domingo 954.

119

FERRER, Ada. Freedom's mirror. Cuba and Haiti in the Age of Revolution. Cambridge: Cambridge University Press, 2014. p. 86-90.
El proceso de negociación con la comunidad cimarrona no fue percibido del mismo modo por todos los arrochelados. Los "estampados se negaban a abandonar su territorio e instalarse en la nueva población, ya que desconfiaban profundamente de los acuerdos alcanzados para la reducción. La divergencia en las estrategias de negociación de los dos grupos de cimarrones se fue incrementando, al mismo tiempo que en la vecina colonia francesa, los fuegos de la revolución comenzaban a prender. Algunas de las medidas tomadas por las autoridades españolas para evitar el contagio revolucionario incrementaron la desconfianza de los cimarrones. ${ }^{112}$ Especialmente, la campaña realizada para la eliminación de los alzados del Petitrout, que fueron capturados por las autoridades españolas en connivencia con algunos miembros de los "criollos del maniel", en agosto de 1790, cercenando una de las vías de comunicación comercial más importante del palenque. ${ }^{113} \mathrm{El}$ comienzo del proceso revolucionario tuvo un efecto fulminante ya que eliminó la influencia de las autoridades francesas en la negociación. Sin embargo, para las autoridades españolas el escenario tampoco era el más favorable. El marasmo en que se sumergió Saint Domingue amenazaba con extenderse a Santo Domingo, por lo que las autoridades intensificaron las negociaciones, urgidos por eliminar un asunto que de enquistarse, podía ser la puerta de entrada en la colonia del proceso revolucionario de la colonia vecina. ${ }^{114}$ El Gobierno político de Santo Domingo era plenamente consciente de su debilidad para hacer frente a la extensión de la gran, por lo que se pusieron en marcha todos los esfuerzos posibles para que la reducción de todos los arrochelados. ${ }^{115}$ Por ello, las autoridades ofrecieron la concesión de un indulto por todos los delitos cometidos hasta la fecha si decidian abandonar las sierras y asentarse en la población de El Naranjo.

La oferta realizada no eliminó las suspicacias de los "estampados", quienes a través de su líder La Fortune, solicitaron permiso a las autoridades dominicanas para que se permitiera a una delegación de cimarrones viajar a Madrid para tener una audiencia con el Rey. El objetivo de tal viaje era establecer el marco de confianza necesario, o al menos el reclamado por los cimarrones, para interpretar que el indulto ofrecido no iba a ser modificado. ${ }^{116}$ Las autoridades españolas negaron tal posibilidad, pero el hecho de que existiese la propuesta indica un cambio en la percepción de lo que podia ser posible, desde el plano político, para los estampados. Su posición en la negociación se hacía progresivamente más fuerte, ya que el colapso de Saint Domingue provocó que un número considerable de esclavos se fugaran siendo acogidos en el maniel. ${ }^{117}$ La disputa entre los diferentes partidos quedó de manifiesto cuando Felipe, el líder de los criollos, reprobó la acogida de 28 esclavos cimarrones que estaban escondidos en las afueras del palenque. En opinión de la autoridades, la actitud de Felipe lo había llevado a la ruina, por ser el partido de los "estampados" cada vez más dominante y por estar mejor pertrechados de armas de fuego. ${ }^{118} \mathrm{Al}$ mismo tiempo, la acción de algunos líderes negros revolucionarios en el Saint Domingue, que respetaban la integridad territorial española, unido a la inacción de las autoridades dominicanas, favoreció un modus vivendi en la zona de frontera que favoreció los contactos comerciales y personales. La acción de los brigantes negros favoreció un clima de entendimiento progresivo, que culminaria con la alianza firmada por los principales líderes de la revolución, Jean François, Biassou y Jacinto, con las autoridades españolas para hacer la guerra a la República francesa a primeros de 1793. ${ }^{119}$ 
120

Carta del Gobernador Joaquin García dando cuenta del conocimiento de la libertad general otorgada a los negros del norte de la colonia francesa (Santo Domingo, 24 de septiembre de 1793) AGI, Santo Domingo 956.

121

DEIVE, Esteban. Los cimarrones del maniel de Neiba, historia y etnografía. Santo Domingo: Banco Central de la República Dominicana, 1985. p. 70 .

122

ATSÉ, Kimou. La rebelión de Galbaud y la libertad general de los esclavos de Saint-Domingue (1793-1794). Nuevo Mundo Mundos Nuevos [En ligne], Débats, mis en ligne le 04 février 2014, consultado el 12 de enero de 2015. URL : http:// nuevomundo.revues.org/66356; DOI : 10.4000/ nuevomundo.66356

123

Informe de los comisionados al D. Joaquín García (Neiba, 8 de agosto de 1791), AGI, Santo Domingo 954.

124

VICTORIA OJEDA, Jorge. Tendencias monárquicas en la revolución haitiana. El negro Francisco Petecou bajos las banderas francesa y española. México DF: Editorial Siglo XXI, 2005. p. 57.

125

Carta del Gobernador de Santo Domingo comunicando la muerte del negro Jacinto (Santo Domingo, 13 de septiembre de 1793), AGI, Santo Domingo 956.

126

MENDEZ QUEIROZ, Elisangela. Op. Cit., p.94
La incorporación de estas tropas al ejército español como "tropas auxiliares negras" provocó un rápido cambio en el escenario de la guerra, permitiendo el avance de las armas hispanas.

Sin embargo, la llegada de las noticias procedentes de la colonia francesa que anunciaban la abolición de la esclavitud en septiembre de 1793 provocó cierta inestabilidad en el orden colonial dominicano. Un amplio sector de las tropas auxiliares juraron fidelidad a la república jacobina francesa, debilitando notablemente la posición española en el conflicto, permitiendo que, ante la delicada situación, muchos esclavos percibieran la coyuntura como favorable para sus intereses ${ }^{120}$. Ante la gravedad de los acontecimientos, las autoridades fueron más proclives a negociar. Por iniciativa del propio rey Carlos IV se expidió la Real Cédula de 17 de noviembre de 1793, que pretendía acabar con el problema. En la misma se ordenaba a las autoridades dominicanas que ofrecieran un tránsito seguro a una comisión de los arrochelados compuesta por dos miembros para que viajaran a Madrid, donde serían recibidos en audiencia por el monarca para disipar cualquier duda sobre el indulto ofrecido. ${ }^{121}$ Sin embargo, la audiencia nunca se celebró, tanto por las reticencias de los arrochelados como por la situación de guerra en la que se encontraba La Española. La llegada del general Galbaud a Saint Domingue, un antiguo plantador de azúcar, y su intento por ocupar el cargo de Gobernador en la colonia en 1793, se tradujeron en un incremento de la inestabilidad, especialmente entre los esclavos alzados del sur de la colonia francesa. ${ }^{122}$ El cambio de alianzas y el nuevo derrotero que siguieron los combates, hicieron temer al Gobernador D. Joaquín García la posible alianza de los negros del maniel con las tropas insurgentes. García tenía informes que señalaban la existencia, más o menos constante, de revolucionarios en el palenque desde el año 1791. Estos, habian introducido fusiles que habian sido repartidos entre los "estampados", dotando de una fuerza de combate superior a los arrochelados. ${ }^{123}$ Esta política, perseguia la adhesión de los cimarrones dentro del proceso revolucionario, captando la fidelidad de sus líderes, al otorgarles una amplia autonomía política y militar. La inquietud sobre la actitud de los estampados varió significativamente al conocerse la muerte del General Jacinto, jefe de las tropas auxiliares negras en la parte de Neiba. ${ }^{124}$ En opinión de Joaquín Garcia, la muerte del general, que había tratado de mantener una actitud ambigua en el conflicto al negociar con todas las partes, suponía un ejemplo "para los demás negros, la ninguna confianza que ofrecen los mulatos, ni los comisarios civiles en sus promesas y contendrá a muchos de confiarse de vanos halagos y esperanzas de comodidad". 125

En este clima de incertidumbre, depositar confianza en alguno de los actores del conflicto era sumamente arriesgado. Para los estampados, el tiempo para negociar con las autoridades españolas había terminado, dado el cambiante y confuso panorama que los acontecimientos estaban mostrando. A pesar de ello, la Real Cédula de 18 de diciembre de 1793 concedió el indulto a todos los miembros del maniel de todos los delitos que hubieran podido cometer hasta la fecha, ${ }^{126}$ tal vez como un medio de prevenir una hipotética alianza de los arrochelados con los revolucionarios. La creciente presión de las tropas británicas, culminada con la toma de Portau-Prince en junio de 1794, provocó que las sierras de Bahoruco se convirtieran en refugio de revolucionarios que huian del impetu de las tropas inglesas. Tras alguna breve escaramuza con los brigantes comandados por Toissant Lóverture, que tras haber jurado fidelidad a la república francesa 
Carta del Capitán Ignacio Caro (Neiba, 11 de junio de 1794), AGI Santo Domingo 1102.

128

Informe del Gobernador de Santo Domingo de haber dado comienzo los ingleses las hostilidades (Santo Domingo, 3 de marzo de 1797) AGI, Santo Domingo 960.

129

ELLER, Ann. All would be equal in the effort: Santo Domingo's Italian Revolution, Independence and Haiti, 1809-1822. Journal of Early American History, Dundee, Vol. 1, Issue 2, p. 121, July, 2011

\section{0}

Real Orden de 31 de marzo último, para reducir a vivir en la antigua población de San Cristóbal del Naranjo varias familias de negros, que desde la cesión de esta isla a la República Francesa la habian abandonado (Santo Domingo, 4 de agosto de 1813), AGI, Santo Domingo 962.

131

DEIVE, Carlos Esteban. El cimarronaje en la colonia española de Santo Domingo. Mar Océana, Madrid, 24, № 8, p. 76, 2008. había acudido a la población de El Naranjo en busca de bastimentos, los arrochelados del maniel permanecieron en la sierra que tan bien conocian y en la que podrian defenderse ante eventuales ataques. ${ }^{127}$ El escaso grado de confianza que los estampados profesaban a los diferentes actores del conflicto haitiano incidió en su decisión de permanecer en su territorio. De otro lado, y pese a los avatares revolucionarios, la población de El Naranjo terminó conformándose con 123 de los arrochelados, un número muy similar a los que aparecieron en el censo de 1785. Este dato nos remite a preguntarnos sobre el grado de fidelidad del mismo, ya que si el partido de los "estampados" era el más numeroso y éstos se habian negado a bajar de las sierras ¿cómo es posible que el número de criollos del maniel se acercara tanto al censado? ¿Acaso la refutación de la negociación por parte de los estampados trajo implícito que no hicieran acto de presencia en el censo y que su número reflejara, con alguna pequeña excepción, el de los criollos?

A pesar de algún hostigamiento protagonizado por hateros vecinos, que provocó la salida de algunos de los residentes, el pueblo del Naranjo sólo fue abandonado completamente tras la firma del tratado de Basilea, cuando las tropas británicas ocuparon Neiba y encarcelaron al cura Bobadilla, su principal valedor en la reducción. ${ }^{128}$ Sus moradores se dispersaron quedando el pueblo, en principio, en el abandono. Sin embargo, tras la restitución de la soberanía española en 1809, y en un ambiente de permanente inestabilidad política, la presencia de población de origen cimarrón en la capital fue percibida como un peligro. ${ }^{129}$ El gobierno colonial dominicano dispuso que se buscase a las personas que habían compuesto el pueblo y se radicaran nuevamente en él, ${ }^{130}$ reubicando con éxito la población de negros libres en 1813. ${ }^{131}$

\section{A modo de recapitulación}

En el proceso de negociación para la reducción del maniel de Bahoruco intervinieron, de manera decisiva, las autoridades españolas, francesas así como los cimarrones. El clima de aparente entendimiento forjado entre las dos monarquías quedó ratificado en una serie de tratados internacionales, los conocidos pactos de familia, que, además de establecer las pautas para la colaboración militar en caso de conflicto armado, también sancionaba una serie de aspectos concernientes a las relaciones de territorios o súbditos de ambas coronas. La isla de La Española, dividida política en territorios correspondientes a ambas monarquías, se erigió en uno de los escenarios donde las relaciones diplomáticas cobraron mayor importancia. Sobre todo porque Saint Domingue se había convertido, a lo largo del siglo XVIII, en la principal colonia esclavista de la monarquía francesa. La entrada masiva de mano de obra esclava, favoreció que, hasta mediados del siglo XVIII, se incrementara el fenómeno del cimarronaje. Las autoridades francesas rediseñaron el sistema de vigilancia, represión y coacción de los esclavos fugados, reduciéndolo sensiblemente, si bien algunos de estos esclavos fugados terminaron por cruzar la frontera e instalarse en las sierras de Bahoruco, en el Santo Domingo español. Allí, conformaron un maniel que se asentó en el territorio y que resistió las diversas campañas que tanto la autoridades españolas como francesas lanzaron para su destrucción. Ante la incapacidad para eliminarlo, las cortes española y francesa llegaron a un punto de acuerdo para iniciar una ronda de negociaciones encaminadas su disolución, el reconocimiento de la libertad para los arrochelados y su instalación en un pueblo de negros libres en Saint Domingue. Sin embargo, los 
GEGGUS, David Patrick. Haitian Revolutionary Studies. Bloomington: Indiana University Press, 2002. p.73-74.

133

GEGGUS, David Patrick. Slavery, War and Revolution in the Greater Caribbean. GASPAR, David Barry and GEGGUS, David Patrick (eds.). A Turbulent Time. The French Revolution and the Greater Caribbean. Bloomington: Indiana University Press, 1997. p.20. habitantes del maniel no confiaron en las autoridades francesas, por lo que el principio de acuerdo quedó roto, protagonizando en los años siguientes la negociación las autoridades españolas, especialmente las eclesiásticas. Sin embargo, esta nueva ronda de negociaciones avanzó lentamente, en buena medida por las estrategias políticas de los habitantes del maniel.

La comunidad cimarrona no conformaba un corpus político unificado, sino que estaba dividida en dos grupos con identidad definida, líderes diferenciados y propuestas políticas divergentes, en base a su experiencia vital bajo la esclavitud o como esclavos fugitivos. A lo largo del proceso de negociación, que se vio seriamente afectado por la revolución haitiana, los posicionamientos políticos de los dos grupos de cimarrones fue discordante. Los autodenominados como "criollos del maniel" aceptaron los términos de la negociación que las autoridades dominicanas les brindaban. En la misma, se reconocía su condición jurídica de hombres libres y se les otorgaba tierras para su fomento, asentándose en la población de El Naranjo. Por el contrario, los denominados como "estampados" fueron reticentes a la reducción. Cuando los fuegos de la revolución llegaron a la región, ambos grupos establecieron estrategias encaminadas a su preservación en base a intereses particulares, si bien ninguno optó por sumarse de manera abierta y decidida a la rebelión. Este aspecto vendría a confirmar la propuesta de David Geggus en cuanto a la escasa conexión del cimarronaje con el momento inicial del proceso revolucionario. ${ }^{132}$ Las políticas de los cimarrones fueron ambiguas, basadas en el oportunismo, buscando, sobre todo, su supervivencia como grupo, más allá de causas generales que podían concernir al resto de los esclavos que se alzaron en Saint Domingue. ${ }^{133}$ Así, los "estampados" permanecieron en el territorio cimarrón como fórmula más segura para su supervivencia, manteniendo esporádicos contactos con los agentes del conflicto, pero afianzando su presencia en las sierras de Bahoruco, convertidas, de facto, en territorio cimarrón durante buena parte del siglo XIX. De manera paralela, el pueblo de El Naranjo, fruto de la reducción que habian protagonizado los "criollos del maniel", fue abandonado ante el avance de las tropas británicas, si bien sólo de manera temporal, ya que terminó reinstalándose parte de su población original tras la restitución de Santo Domingo a la soberanía española, conformando el origen de una población que ha subsistido hasta el presente.

\section{Bibliografía}

ARAUJO, Ana Lucia. Dahomey, Portugal and Bahia: King Adandozan and the Atlantic Slave Trade. Slavery \&t Abolition, Oxford, 33, 1, 2012.

ANDERSON, Richard; BORUCKI, Alex; DOMINGUES DA SILVA, Daniel; ELTIS, Davis; LACHANCE, Paul; MISEVIC, Philip and OJO, Olantuji. Using African Names to Identify the Origins of Captives in the Transatlantic Slaves Trade: Crowd-Sourcing and the Registers of Liberated Africans, 1808-1862". History in Africa, Cambridge, Available on CJO 2013, doi:10.1017/hia.2013.3

ATSÉ, Kimou. La rebelión de Galbaud y la libertad general de los esclavos de Saint-Domingue (1793-1794). Nuevo Mundo Mundos Nuevos [En ligne], Débats, mis en ligne le 04 février 2014.

La presencia Africana en la independencia de Haiti.(1791-1820).

Tesis de doctorado en Historia de América Latina, Facultad de Humanidades, Universidad Pablo de Olavide, Sevilla, 2012. 
BARCIA, Manuel. West African Warfare in Bahia and Cuba: Soldier Slaves in the Atlantic World, 1807-1844. Oxford: University Press of Oxford, 2014.

BARCIA, Manuel. West African Islam in Colonial Cuba. Slavery \& Abolition, Oxford, 35:2, 2014.

BLACKBURN, Robin. The Making of New World Slavery: From the Baroque to the Modern, 1492-1800. Londres: Verso, 2002.

BARTHÉLÉMY, Gerard. Le rôle des Bossales dans I'emergence d'une culture marronage en Haïti. Cahiers d'Études Africaines, Paris, Vol. 37, Cahier 148, La Caraïbe: Des îles au continent, 1997.

BASTIDE, Roger. Continuidad y discontinuidad en las sociedades afroamericanas. CUNIN, Elisabeth (ed). Textos en diáspora. Una antología sobre afrodescendentes en América. México DF: Instituto Nacional de Antropología e Historia, 2008.

BELMONTE POSTIGO, José Luis. Las dos caras de una misma moneda. Reformismo y esclavitud en Santo Domingo a fines del periodo colonial. Revista de Indias, Madrid, Vol. 74, № 261, 2014.

. De cómo la costumbre articula derechos. Esclavos en Santo Domingo a fines del periodo colonial. In: LAVIÑA, Javier; PIQUERAS Ricardo y MONDEJAR, Cristina (eds.). Afroamérica, espacios e identidades. Barcelona: Editorial Icaria, 2013.

BENEI, Véronique. The Corsair, the Bishop, the Governor and the runaways: Negotiating slavery in early eighteenth century Santa Marta, New Granada. Nuevo Mundo Mundos Nuevos [En ligne], Débats, mis en ligne le 28 mars 2014, consulté le 03 juin 2014.

BERLIN, Ira. From Creole to African: Atlantic Creoles and the Origins of African-American Society in Mainland North America. The William and Mary Quarterly, Williamsburg, Third Series Vol. LIII: 2, April, 1996.

CIAPPARA, Frans. Religion, Kinship and Godparenthood as elements of Social Cohesion in Qrendi, a late eighteenth-century Maltese parish. Continuity and Change, Cambridge, Vol. 25, Special Issue 1, 2010.

CURTIS, Isaac. Masterless People: Maroons, Pirates and Commoners. In: PALMIE, Stephan and SCARANO, Francisco (eds.), The Caribbean. A History of the Region and its People. The University of Chicago: Chicago Press, 2011.

DEBBASCH, Yvan. Le maniel: Further Notes. In: PRICE, Richard (ed.) Maroon Societies. Rebel Slave Communities in the Americas. Baltimore: The John Hopkins University Press, 1996.

DUBOIS, Laurent. Avengers of the New World. The Story of Haitian Revolution. Cambridge: The Belknap Press of Harvard University Press, 2004.

ELLER, Ann. All would be equal in the effort: Santo Domingo's Italian Revolution, Independence and Haiti, 1809-1822. Journal of Early American History, Dundee, Vol. 1, Issue 2, July, 2011.

ESTEBAN DEIVE, Carlos. El cimarronaje en la colonia española de Santo Domingo. Mar Océana, Madrid, 24, № 8, 2008. Los cimarrones del maniel de Neiba, historia y etnografía. Santo Domingo: Banco Central de la República Dominicana, 1985.

FALL, Yoro. Historiografía, sociedades y conciencia histórica de África. In: DJOGBÉNOU, Adonon Fabien. Hacia el universo negroafricano. México D.F.: Universidad Nacional Autónoma de México, 2003.

FERRER, Ada. Freedom's mirror. Cuba and Haiti in the Age of Revolution. Cambridge: Cambridge University Press, 2014. 
FICK, Carolyne. Making Haiti: Saint Domingue Revolution from below. Knoxville: University of Tennesse Press, 1990.

GEGGUS, David Patrick. Haitian Revolutionary Studies. Bloomington: Indiana University Press, 2002.

Slavery, War and Revolution in the Greater Caribbean. In: GASPAR, David Barry and GEGGUS, David Patrick. A Turbulent Time. The French Revolution and the Greater Caribbean. Bloomington: Indiana University Press, 1997.

. Slave Resistance in the Spanish Caribbean in the Mid-1790. In: GASPAR, David Barry and GEGGUS, David Patrick. A Turbulent Time, The French Revolution and the Greater Caribbean, Bloomington: Indiana University Press, 1997.

. Sugar and Coffee Cultivation in Saint Domingue and the Shaping of the Slave Labor Force. In: BERLIN, Ira and MORGAN, Philip. Cultivation and Culture: Labor and the Shaping of Slave Life in the Americas. Charlottesville: University of Virginia Press, 1993.

GOMES, Flavio. Africanos, naciones y cofradías en Rio de Janeiro, siglos XVIII y XIX. Boletín Americanista, Barcelona, Año LXI, № 63, 2011. . Etnogénesis y ocupación colonial: Africanos, indígenas, criollos y cimarrones en Brasil, siglo XVIII. Anuario IEHS, Tandil, 26, 2011. . A hidra e os pântanos. Mocambos, quilombos e comunidades de fugitivos no Brasil (séculos XVII-XIX). São Paulo: Editora UNESP, 2005.

GÓMEZ, Pablo F. The Circulation of Bodily Knowlodge in the SeventeenthCentury Black Spanish Caribbean. Social History of Medicine, Oxford, Vol. 26, № 3, 2013.

GONZÁLEZ, Raymundo. De esclavos a campesinos. Vida rural en Santo Domingo colonial. Santo Domingo, Archivo General de la Nación, Vol. CXLVIII, 2011.

GUTIÉRREZ ESCUDERO, Antonio. Hispaniola's turn to tobacco: Products from Santo Domingo in Atlantic Commerce. In: ARAM, Bethany and YUN, Bartolomé (eds.). Global Goods and the Spanish Empire, 14921824. Circulation, Resistence and Diversity. Basingstoke: Palgrave Macmillan, 2014.

El tabaco de Santo Domingo y su exportación a Cádiz y Sevilla, Revista Hispanoamericana. Revista Digital de la Real Academia Hispano Americana de Ciencias, Artes y Letras, No1, 2011. . La estructura económica de Santo Domingo, 1500-1795. In: MOYA PONS, Frank (coord.) . Historia de la República Dominicana. Madrid: Doce Calles, 2010. Acerca del proyectismo y del Reformismo borbónico en Santo Domingo. Temas Americanistas, Sevilla, № 13, 1997.

HALL, Gwendolyn Midlo. Slavery and African Ethnicities in the Americas. Chapel Hill: The University of North Carolina Press, 2005.

HAHN, Steven. The Political Worlds of Slavery and Freedom. Cambridge: Harvard University Press, 2009.

HELLY, Denise, BARSKI, Robert y FOXEN, Patricia. Social Cohesion and Cultural Plurality. The Canadian Journal of Sociology, Vol. 28, № 1, Special Issue on Social Cohesion in Canada, Winter, 2003.

HERNÁNDEZ DE LARA, Odlanyer; RODRÍGUEZ TÁPANES, Boris y ARREDONDO ANTUNES, Carlos. Esclavos y cimarrones en Cuba: Arqueología Histórica en La Cueva del Grillete. Buenos Aires: Aspha Editores, 2014. 
JAUREGUI, Carlos. El negro comegente: Terror, colonialismo y etno-política. Afro-Hispanic Review, Nashville, Vol. 28, №1, Spring, 2009.

KARRAS, Allan. Transgressive Exchange. Circumventing Eighteenth Century Atlantic Commercial Restrictions or the Discount of Monte Christi. In: BENTLEY, Jerry, BRIDENTHAL, Renate and WIGEN, Karen. Seascapes. Maritime Histories, Littoral Cultures and Transoceanic Exchanges. Honolulu: University of Hawaii Press, 2007.

KOUASSI DENOS, Koffi. Raza y cultura negra en América Latina. Latinoamérica. Anuario de Estudios Latinoamericanos. Mexico DF, № 20, 1989.

LANDERS, Jane. Maroon Ethnicity and Identify in Ecuador, Colombia and Hispaniola. Conference paper delivered for the Latin American Studies Association, Miami, 2000.

LA ROSA CORZO, Gabino. Tatuados. Deformaciones étnicas de los cimarrones en Cuba. La Habana: Fundación Fernando Ortíz, 2011. . Aproximaciones antropológicas a las bandas cimarronas de las ciénagas de Cuba. Gabinete de Arqueología, La Habana, Boletín №7, Año 7, 2008. - Armas y tácticas de los cimarrones en Cuba. Reporte de investigación, La Habana, №2, Instituto de Ciencias Históricas, Academia de la Historia, 1989.

LAVIÑA, Francisco Javier. Etnicidad y resistencia a la esclavitud. In: CWIK, Christian; LAVIÑA, Francisco Javier; ZEUSKE, Michael (eds.) Esclavitud, huida y resistencia en Cuba. Berlín: Wissenschaftlicher Verlag, 2013. Alimentación y cimarronaje en Vuelta Abajo. Notas sobre el diario de un Rancheador. Boletín Americanista, Barcelona, 37, 1988.

LIENHARD, Martin. Agrestes e irreligiosos. Los cimarrones del maniel de Neiva (Santo Domingo 1784-1795). In: Disidentes, rebeldes, insurgentes Resistencia indigena y negra en América Latina. Ensayos de historia testimonial. Madrid: Iberoamericana Vervuert, 2008.

LOVEJOY, Paul. Comparación de la vida de dos musulmanes en América: Muhammad Kaba Saghanaghu y Mahommah Gardo Baquaqua. Estudios de Asia y África, México D.F., Vol XLIII, № 1, enero- abril 2008. LUCENA SALMORAL, Manuel. Leyes para esclavos: el ordenamiento jurídico sobre la condición, tratamiento, defensa y represión de los esclavos en las colonias de la América española. Madrid: Editorial Tavera, 2000.

MENDES QUEIROZ, Elisangela. Ao sul do fronteira cimarrón: 0 processo de redução dos negros do maniel de Neiba na Ilha de Espanhola (1782-1795). Disertación (maestrado en Historia Social). Facultad de Filosofía y Letras y Ciencias Humanas de la Universidad de São Paulo, São Paulo, 2012.

MILLER, Joseph. Retention, Reinvention and Remembering: Restoring Identities through Enslavement in Africa and under Slavery in Brazil. CURTO, Jose and LOVEJOY, Paul (eds.) Enslaving Connections. Changing Cultures of Africa and Brazil during the Era of Slavery. Amherst: Humanity Books, 2004

MINTZ, Sidney. The Socio-Historical Background to Pidginization and Creolization. In: HYMES, Dell (ed.) Pidginization and Creolization of Languages: Proceedings of a Conference Held at the University of the West Indie. Cambridge:Cambridge University Press ,1974.

MOREAU DE SÀINT- MARI, M.I.E. The Border Maroons of Saint Domingue: Le Maniel. In: PRICE, Richard (ed.) Maroon Societies. Rebel Slave 
Communities in the Americas. Baltimore: The John Hopkins University Press, 1996.

MOYA PONS, Frank. Historia del Caribe, azúcar y plantaciones en el mundo atlántico. Santo Domingo: Ediciones Ferilibro, 2008.

Manual de Historia Dominicana. Santo Domingo: Caribbean

Publishers, 2008.

NESSLER, Graham. The shame of the nation. The force of the reenslavement and the law of the slavery under the regime of Jean Louis Ferrand in Santo Domingo, 1804-1809. New West Indian Guide, Leiden, Vol. 86, 1-2,2012.

OJO, Olatunji. Beyond Diversity: Women, Scarification and Yoruba Identity. History in Africa, Cambridge, 35, 2008.

ORTEGA, José G. Freedom, Identity and the Social History of Empire in Atlantic Cuba, 1795-1817, SlaveryEtAbolition, Oxford, Vol. 35, Issue 2, 2014

0'TOOLE, Rachel. From the Rivers of Guinea to de Valleys of Peru. Becoming a Bran Diaspora within the Spanish Slavery. Social Text 92, Durham, Vol. 95, № 3, Fall 2007.

PAIVA, Eduardo França. Escravidão, dinâmicas de mestiçagens e o léxico ibero americano. Portuguese Journal of Political Science and International Relations, Braga, № 10, 2013.

Allah and the New World: Slaves and Free Islamized in the American Colonial Universe. In: Elisabeth Herrmann-Otto; Marcel Simonis; Alexander Trefz. (Org.). Sklaverei und Zwangsarbeit zwischen Akzeptanz und Widerstand. Hildesheim: Georg Olms Verlag, 2011.

PESSOA DE CASTRO, Yeda. Lenguas africanas. Factor de resistencia en la ruta del esclavo. Del Caribe, Santiago del Cuba № 28,1998.

PINTO, Antonio. Una vecindad controvertida: Las relaciones bilaterales en La Española hasta 1795. Seminario de Investigación, Madrid, Departamento de Historia Contemporánea de la Universidad Complutense de Madrid, 25 de mayo de 2010.

PRICE, Richard. The miracle of Creolization: A Retrospective. New West Indian Guide, Leiden,Vol. 75, № 1\&t2, 2001.

REID, Michelle. The Yoruba in Cuba. Origins, Identities and Transformations. In: FALOLA, Toyin and CHILD, Matt D. (eds). The Yoruba Diaspora in the Atlantic World. Bloomington: Indiana University Press, 2004.

REIS, João José. African Nations and Cultural Practices in NineteenthCentury Salvador, Bahia. The 12th Annual Gilder Lehrman Center International Conference at Yale University, New Haven, 29-30 October, 2010.

RUPERT, Linda M. Marronage, Manumission and Maritime Trade in the Early Modern Caribbean. Slavery \& Abolition, Oxfordshire, 30, 3, 2009.

SÁNCHEZ VALVERDE, Antonio. Idea del Valor de la Isla Española y utilidades que de ella puede sacar su Monarquía. Madrid: Imprenta de D. Pedro Marín, 1785.

SCHWARTZ, Stuart B. Cantos and Quilombos. A Hausa Rebellion in Bahia, 1814. In: LANDERS, Jane G. and ROBINSON, Barry M. (eds.). Slaves, Subjects and Subversives: Blacks in Colonial Latin America. Albuquerque: University of New Mexico Press, 2006.

SWEET, James. Recreating Africa. Culture, Kinship and Religion in the African Portuguese World 1441-1770. Chapel Hill: The University of North Carolina Press, 2003. 
SEVILLA SOLER, Rosario. Santo Domingo, frontera francoespañola. Consecuencias de la presencia francesa en la Isla de la Española. Revista de Indias, Madrid, Anexos 4, 1991. . Santo Domingo tierra de frontera, 1750-1800. Sevilla: Escuela de Estudios Hispanoamericanos, 1980.

THORNTON, John. African Dimensions of the Stono Rebellion. The American Historical Review, Oxfordshire, Vol.96, №4, October 1991, p. 11011113. MOSER, Bruce. Rebellion, Marronage and Jihad. Estrategies of Resistance to Slavery on the Sierra Leone Coast. Journal of African History, Cambridge, 48, 2007.

. I am subject of the King of Kongo: African Political Ideology and the Haitian Revolution. Journal of World History, Honolulu, Vol. 4, № 2, Fall, 1993.

TOMICH, Dale. Commodity Frontiers, Conjuncture and Crisis: The Remaking of the Caribbean Sugar Industry, 1783-1866. In: LAVIÑA, Javier and ZEUSKE, Michael (eds). The Second Slavery. Mass Slaveries and Modernity in the Americas and in Atlantic Basin, Berlin, Lit Verlag, 2014.

VAN NORMAN, William. The Process of Cultural Change Among Cuban Bozales During the Nineteenth Century. The Americas, Berkeley, Vol. 62, № 2, October 2005.

VICTORIA OJEDA, Jorge. Tendencias monárquicas en la revolución haitiana. El negro Francisco Petecou bajos las banderas francesa y española. México DF, Editorial Siglo XXI, 2005.

WIDMER, Rudolf. El Hato ganadero del Este en la economía de Santo Domingo en el siglo XVIII. Con Antonio Sánchez Valverde en San Dionisio de Higüey, Clío, Órgano de la Academia Dominicana de la Historia, Santo Domingo, № 165, enero-junio 2003.

ZEUSKE, Michael. Saint Domingue en Cuba: El levantamiento en Banes el 13-14 de agosto de 1833. In: CWICK, Christian; LAVIÑA, Francisco Javier; ZEUSKE, Michael (eds.), Esclavitud, huida y resistencia en Cuba. Berlin: Wissenschaftlicher,Verlag, 2013. The Names of Slavery and Beyond: The Atlantic, The Americas and Cuba. In: SCHEMEIDER, Ulrike; FÜLLBERG-STOLBERG, Katja and ZEUSKE, Michael (eds.) The End of Slavery in Africa and the Americas. A Comparative Approach. Munster-Hamburg-Berlin-Wien-London, LIT-Verlag, 2011.

Estructuras e identidad en la segunda esclavitud: el caso cubano 1800-1940. Historia Crítica, Bogotá, № 24, 2003. Hidden markers, open secrets: on naming, race-marking and racemaking in Cuba. New West Indian Guide, Leiden, Vol. 76, № 3-4, 2002. 